\title{
Application of an Integrated Model Based on Bivariate and Multivariate Method in Landslide Susceptibility Mapping
}

$\mathrm{Han} \mathrm{Hu}$

Jilin University

Changming Wang ( $\nabla$ wangcm@jlu.edu.cn )

Jilin University

Zhu Liang

Jilin University

\section{Research Article}

Keywords: Landslide Susceptibility, Certainty factor, Frequency ratio, Information value, GIS, Logistic regression

Posted Date: November 24th, 2020

DOI: https://doi.org/10.21203/rs.3.rs-107923/v1

License: (c) (i) This work is licensed under a Creative Commons Attribution 4.0 International License. Read Full License 


\section{Application of an integrated model based on bivariate and 2 multivariate method in landslide susceptibility mapping}

3 Han $\mathrm{Hu}^{\mathrm{ab}}$, Changming Wang ${ }^{\mathrm{a}^{*}}$, Zhu Liang ${ }^{\mathrm{a}}$

4 College of Construction Engineering, Jilin University, Changchun 130026, People's Republic of China ${ }^{\mathrm{a}}$

5 School of Geomatics and Prospecing Engineering, Jilin Jianzhu University, Changchun 130118,

$6 \quad$ People's Republic of China ${ }^{b}$

7 Corresponding author*: Changming Wang

$8 \quad$ E-mail address: wangcm@jlu.edu.cn

9

Abstract: Landslides usually result in human losses and economic damages in mountainous areas especially for Himalayan areas. Landslide susceptibility mapping (LSM) is a key approach for avoiding hazard and risk. This study aims to explore an improved model combining multivariate and bivariate statistical methods for LSM. Four models were established as logistic regression (LR), LR integrated with certain factor (CF), LR integrated with frequency ratio (FR) and LR integrated with information value method (IV) and their performance was compared in LSM.

Firstly, a landslide inventory map with 313 determined landslide events was prepared and 12 predisposing factors were selected. Secondly, the dataset was randomly divided into two parts, $75 \%$ of which was used for modeling and $25 \%$ for validation. Finally, area under the curve (AUC) and statistical metrics were applied to validate and compare the performance of the models. Results show that the performance of IVLR model is the best (AUC 0.792 and accuracy $=78.8 \%$ ). Besides, the LSM constructed by IVLR model did a reasonable job at predicting the distribution of 
susceptible areas. It identified the major factors and intervals of high susceptibility that profile curvature greater than 0.1 , less than $2 \mathrm{~km}$ from the stream, maximum elevation difference greater than $1200 \mathrm{~m}$ and rainfall between 440 and $450 \mathrm{~mm}$ were prone to landslide. The conclusion reveals that the quality of LSM can be improved by comparing and combining the bivariate and multivariate methods, which serve as a more effective guide for land use planning in the study area or other highlands where landslides are frequent.

Key words: Landslide Susceptibility; Certainty factor; Frequency ratio; Information value; GIS; Logistic regression

\section{Introduction}

Landslide is a sudden geological phenomenon widely distributed across the world, causing direct or indirect damages to property and injuries or fatalities of people residing in the area ${ }^{1,2,3}$. The frequency and scale of landslide outbreaks in China are far beyond than that of other countries in the world ${ }^{4,5}$. The prevention measures need to identify the existing landslides for spatial zonation ${ }^{6}$. Generally, damages can possibly be controlled by prediction where disasters may occur in the future ${ }^{7}$. Therefore, landslide susceptibility mapping (LSM) is considered as an effective approach to avoid hazards and risk.

The approaches for landslide susceptibility modeling can be broadly classified as qualitative (knowledge-driven methods or physically based methods) and quantitative (data-driven methods) 8,9. Data-driven methods can be categorised as bivariate methods (like frequency ratio (FR), certainty factor (CF) and information value (IV)) and multivariate methods (like logistic regression (LR), factor analysis and cluster analysis $)^{10,11,12,13}$. Qualitative methods are mostly 
subjective and limited to apply in the small-scale areas. In recent years, geographic information system (GIS) and computing techniques increasingly developed and statistical-based methods are becoming popular. New machine learning methods like AdaBoost, extremely randomized tree and support vector machine have also been noticed due to their ability of solving the problem of non-linear geo-environmental issues without necessary assumptions compared to traditional multivariate methods ${ }^{14,15}$. However, the relationship between landslide occurrences and landslide related factors are determined by training rather than inference, which is also called "the black box" operation and the methods lack credibility and interpretability in practice ${ }^{16}$.

Bivariate methods are famous for its simplicity and applicability to explore the correlations between landslides and predisposing factors, although multivariate methods generally perform better in terms of accuracy ${ }^{17,18,19}$. The FR, CF and IV methods not only produce landslide susceptibility maps but also serve to explore the vulnerabilities to landslide failure of individual landslide predisposing factors by the corresponding values calculated for each interval. However, the potential relationship between the various conditioning factors is complex having different impacts on landslide susceptibility. Bivariate methods cannot determine the relative weights between different factors. Therefore, it is necessary to optimize the bivariate methods.

LR model as one of the representatives of multivariate methods has been well verified in the $\mathrm{LSM}^{20,21}$. It models between various dependent variables and multiple independent variables which is applicable in LSM. However, the final mathematical expression cannot comprehensively express the correlation between different intervals of various factors and landslides occurring. Therefore, it is meaningful to combine the bivariate and multivariate statistical methods to better analyze the conditioning factors and we aim to compare the performance of three ensembles 
models (CFLR, FRLR and IVLR) for the most suitable one for LSM. The Louza County in Southeastern Tibet is selected as the study area where shallow landslides are frequent due to topographic and geological conditions. The value of AUC, statistical metrics and kappa coefficient were combined to assess the comparison of performance of these models.

\section{Materials}

\subsection{Study area}

Luoza county is situated in Shannan city, Southeastern Tibet. It ranges from $90^{\circ} 59^{\prime} \mathrm{E}$ to $91^{\circ} 15^{\prime} \mathrm{E}$ of longitude and $28^{\circ} 26^{\prime} \mathrm{N}$ to $29^{\circ} 56^{\prime} \mathrm{N}$ of latitudes (Fig. 1). It has a population of more than 4500 , covering an area of $870.9 \mathrm{~km}^{2}$. The study area belongs to temperate semi-humid climate zone and the annual rainfall is $454 \mathrm{~mm}$ which concentrated mainly in July to September.

Topographically, it is a typical highland area and the highest elevation is 6696 while the lowest is $3488 \mathrm{~m}$ and slope angle ranges from $0^{\circ}$ to $73^{\circ}$. During our field investigation, four lithologies were common: gray sandstone from Cretaceous Gucuo (K1g), pellet micrite from Jurassic $\left(\mathrm{J}_{2 \mathrm{n}}\right)$, limestone from Triassic $\left(\mathrm{T}_{3}\right)$ and Quaternary deposits. The landslides in the area belong to rain-induced landslide, which are a threat to local villagers and economies commonly

(Fig. 2 and Fig. 3).

\subsection{Data preparation}

\subsubsection{Landslide inventory}

An important assumption in the statistically-based methods for LSM is that landslides have 
more chance to occur again under the conditions which led to the landslides before or at present ${ }^{22}$. Therefore, a complete and accurate landslide inventory which shows the locations of landslides is essential ${ }^{7}$. Inventory data comes from remote sensing image (Fig. 4), historical records and extensive field survey. All landslides are bounded by polygons containing the whole landslide perimeter and 313 landslide polygons were identified. Model training and testing was based on commonly applied 1:1 sampling strategy ${ }^{23}$. Therefore, the total number of samples is 626 , including 313 landslide locations and 313 non-landslides samples. Non-landslide samples were optionally selected far from the landslide areas.

\subsubsection{Conditioning factors}

Depending on the characteristics of the study region, the availability, reliability and practicality of the data, 12 conditioning factors were selected: annual rainfall (F1), maximum elevation difference (F2), altitude (F3), plan curvature (F4), profile curvature (F5), slope angle (F6), topographic wetness index (F7), distance to roads (F8), distance to faults (F9), distance to streams (F10), slope aspect (F11) and lithology (F12) ${ }^{24}$.

Rainfall is the unique triggering factor considered and it has been applied for many times. The thematic map was generated by ordinary kriging interpolation in ArcGIS and 12 precipitation stations near the study area provided related information. The thematic was reclassified into 4 classes (Fig. 5a).

Maximum elevation difference reflects potential kinetic energy of a slope unit, which was calculated in ArcGIS 10.2. The thematic map was reclassified into 6 classes by $300 \mathrm{~m}$ intervals

(Fig. 5b). Altitude has influence on both rainfall and vegetation ${ }^{25,26}$ and elevation in the area was 
divided into four subclasses by $500 \mathrm{~m}$ intervals (Fig. 5c). Curvatures are essential to the geometry of slopes, which provides valuable information about erosion and deposition ${ }^{27}$. Both the plan and profile curvatures were reclassified into six classes (Fig. 5d and 5e). TWI is another morphometric parameter that represents basic terrain ${ }^{28}$, which was divided into six categories (Fig. 5g). Slope angle is another considerable factor, which controls shear strength on potential slide surface and the subsurface flow ${ }^{29}$ and was reclassified into five classes by $10^{\circ}$ intervals (Fig. 5f). Six topographical related factors were extracted from the digital elevation model (DEM) with the spatial resolution of $30 \mathrm{~m}$.

Faults act as potential weak planes in slopes which could reduce bulk-rock strength and distance to fault were constructed with six classes for $<2000,2000 \sim 4000,4000 \sim 6000,6000 \sim 8000$, 8000 10000 and $>100000 \mathrm{~m}$ (Fig. 5i). Similarly, six subclasses of distance to road and distance to river were created in an interval of $2000 \mathrm{~m}$ (Fig. $\mathbf{5 h}$ and $\mathbf{5 j}$ ).

Lithology map with four classes was constructed for Shale with siltstone, Quaternary deposits, Shale with limestone and Pellet micrite (Fig. 5k). It is an important factor in slope stability and was also adopted by several researchers ${ }^{30}$. Slope aspect can initiate great impact on microclimate and has previously been used by researchers ${ }^{17,31}$. It was attributed to eight subclasses and are shown in Fig. $\mathbf{5 l}$.

The lithology as well as the faults information were extracted using an existing 1:50,000 geological map. Roads and rivers network information were obtained from Landsat 8 LOI images. Distance to fault, distance to road and distance to stream were calculated with the Euclidean Distance ArcGIS Tool that measures the distance in meters from each raster unit of the area to the closest vector segment. 


\subsubsection{Choice of mapping units}

Three types of mapping units are commonly applied in LSM: grid cells, slope units and unique-condition units ${ }^{32,33}$. The choice of mapping unit is controversial while grid cells are the most popular ${ }^{34}$. Slope units are better in reflecting the geomorphological and geological condition of a landslide, which comprises the source, transport and accumulation areas of a landslide. Finally, the study area is divided into 2060 slope units with the hydrologic analysis tool in ArcGIS and necessary artificial corrections are accompanied according to remote sensing image.

\section{Methods}

\subsection{LR model}

LR model establishes the nonlinear probabilistic function of binary dependent variables ${ }^{35,36}$.

The data type is not limited and nominal, continuous or a combination of both are feasible ${ }^{37}$, the equation for which can be shown as follow:

$$
\mathrm{p}=\frac{1}{1+e^{-y}}
$$

where $\mathrm{p}$ represents the probability of an event ranging from 0 to 1 ; y represents a linear fitting function as showed below:

$$
\mathrm{y}=b_{0}+b_{1} x_{1}+b_{2} x_{2}+b_{3} x_{3}+b_{n} x_{n}
$$

Where $b_{0}$ is the intercept of the model, $b_{1}, b_{2}, \ldots, b_{n}$ are the partial regression coefficients and $x_{1}$, $x_{2}, \ldots, x_{n}$ are the variables.

LR was modeled in SPSS software and forward stepwise method was applied for exclude the non-significant variables. The values of 12 evaluation factors of all units were extracted as 
independent variables while dependent variables represent the occurrence of landslide event i.e. 1 represents occurrence and 0 represents non-occurrences. The significant values of all variables retained in the last step of the analysis were less than 0.05 and no variables were added.

\subsection{CF method}

$\mathrm{CF}$ is a bivariate statistical method which is commonly used in analyzing the probabilistic relationship between the dependent and independent variables. Accordingly, the classification of landslide-related factors should be determined first with continuous factor values.

CF method is a probability function firstly introduced by Shortliffe and Buchanan ${ }^{10}$ in 1975 and then Heckerman ${ }^{38}$ improved it. The CF method assumes the same as other statistical methods that the conditions for future geological disasters are the same as those for the past. The method for the calculation of the $\mathrm{CF}$ is shown as follow:

$$
C_{F}=\left\{\begin{array}{l}
\frac{P P_{a}-P P_{s}}{P P_{a}\left(1-P P_{s}\right)}, P P_{a} \geq P P_{s} \\
\frac{P P_{a}-P P_{s}}{P P_{s}\left(1-P P_{a}\right)}, P P_{a}<P P_{s}
\end{array}\right.
$$

Where $\mathrm{PP}_{\mathrm{a}}$ represents the ration of the area of landslide of the a-th conditioning factor in a specific interval to the area of a-th factor; $\mathrm{PP}_{\mathrm{s}}$ represents the ratio of the total number (or area) of landslide to the total study area.

The value of $\mathrm{CF}$ ranges from $-1 \sim 1$ on the basis of equation 3. A positive $\mathrm{CF}$ value indicates that the occurrence of landslide is highly certain and the geological environmental conditions are prone to geological disasters. The higher the value, the higher will be the certainty. On the contrary, negative values represent low certainty of landslide.

CFLR model was established in SPSS, which considers the CF value of the units as 
independent variable and the occurrence of landslide as the dependent variable.

168

\subsection{IV method}

The IV method uses the frequency or density of landslides to reflect the magnitude of the hazards of different influencing factors and their sub-intervals. It was first proposed by Yin and $\operatorname{Yan}^{39}$ and the equation 4 shows the method for calculating the information values:

$$
\mathrm{I}_{\left(A_{i-j}\right)}=\operatorname{In} \frac{n_{i-j} / s_{i-j}}{n / s}
$$

Where $\mathrm{i}=1,2,3, \ldots, \mathrm{n} ; \mathrm{j}=1,2,3, \ldots, \mathrm{m} ; \mathrm{n}_{\mathrm{i}-\mathrm{j}}$ represents the area of landslide of the $\mathrm{i}$-th conditioning factor in $\mathrm{j}$-th interval; $\mathrm{s}_{\mathrm{i}-\mathrm{j}}$ represents the area of the $\mathrm{i}$-th conditioning factor in $\mathrm{j}$-th interval; $\mathrm{n}$ represents the total area of landslide and s represents the total area.

The values from IV method can either be positive or negative. If it is positive, it indicates that the factor is conducive to the occurrence of landslide in a specific interval: the greater the IV, the higher the possibility of landslide, and vice versa.

Similarly, the IVLR model was established in SPSS, taking the IV value of the units as independent variable and the occurrence of landslide as the dependent variable.

\subsection{FR method}

The equation allows calculating the FR values of a certain level of a conditioning factor ${ }^{40}$ :

$$
\mathrm{FR}_{\mathrm{i}}=\frac{\frac{\frac{\text { landslide_cells }_{i}}{\text { landslide_cells }_{\text {tot }}}}{\text { no_landslide_cells }}}{\text { no_landslide_cell }_{\text {tot }}}
$$

where $i$ indicates the $i$-th class for each considered variable.

If the FR $>1$, a determined correlation exists between the landslide occurrence and factor 
class and if the FR $<1$ than there will be a reflection of weak correlation. The IV, FR and CF method has produced the corresponding indexes of each class of the 12 control factors as shown in

\section{Table 1.}

Finally, the FRLR model was established by taking the FR values of the units as independent variable and the occurrence of landslide as the dependent variable.

\subsection{Models evaluation}

Models will be unpersuasive without scientific validation. The elaboration of the predictive capability requires a splitting of the available data into training and test data. $75 \%$ of the datasets were randomly chosen for modeling training and $25 \%$ for testing.

Three statistical metrics as accuracy, sensitivity and specificity are applied to evaluate the performance of the models.

$$
A \text { ccuracy }=\frac{T P+T N}{T P+T N+F P+F N}
$$

where True Positives (TP) represents the number of landslide units predicted correctly as unstable, True Negatives $(\mathrm{TN})$ represents the number of non-landslide units predicted correctly as stable, False Positives (FP) represents the number of non-landslide units predicted incorrectly as unstable and False Negatives (FN) represents the number of landslide units predicted incorrectly stable. The area under the receiver operating characteristic curve (AUROC) is another indicator to assess the evaluation effect of LSM.

In this study, both AUC and three statistical evaluation measures were combined to evaluate and validate the models established by LR, CFLR, IVLR and FRLR. 


\section{Results and verification}

\subsection{Performance and comparison of different models}

Z-score normalization method was applied to standardize the data and to eliminate the impact

of different dimensions (units) before modeling. Besides, a correlation analysis was conducted to test collinearity among the independent variables. The variance inflation factor (VIF) is a common applied index ${ }^{41}$. If VIF is greater than 5 or 10 , it indicates that there is severe collinearity between the selected variables.

Table 2 showes the VIF values of the chosen independent variables and indicates that no multicollinearity exists among the chosen variables. SPSS also provides the test indexes that square values and the Nagelkerke $\mathrm{R}$ square value indicated that the independent variables can explain the dependent variables, having values of $57.7 \%$ and $50.3 \%, 63.3 \%$ and $74.4 \%, 66.2 \%$ and 68.2\%, 67.2\% and 69.5\% for LR, CFLR, FRLR and IVLR models respectively (Table 4).

The IVLR model achieves the highest value of sensitivity (81.6\%), followed by the FRLR model (sensitivity=80.9\%), the CFLR model (sensitivity=76.8\%) and LR model (sensitivity $=74.2 \%)$ as shown in Table 5. The FRLR model showed the best performance for specificity with the value of $84.2 \%$, followed by IVLR model $(83.5 \%)$, CFLR model $(81.5 \%)$ and LR model (80.7\%). The IVLR model performed the best in terms of accuracy and ROC with the values of $82.6 \%$ and 0.829 (Table 6) . However, LR model performed the worst with the values of $77.3 \%$ and 0.781 . The FRLR model also performed well with the value of $82.4 \%$ and 0.820 , followed by CFLR model (78.7\% and 0.800$)$. 
model. It was found that IVLR model performed the best with the highest values of sensitivity, noticed that hybrid models were better than the single model in terms of prediction capacity. close and better than CFLR model.

\subsection{Evaluation of influencing factors}

\subsubsection{Application of bivariate methods} percentages of landslide area for $440 \sim 450 \mathrm{~mm}$ and $>450 \mathrm{~mm}$ were $52.05 \%$ and $38.81 \%$ respectively, which means that $90 \%$ of landslide areas were distributed among the two class of rainfall and the IV value of these two classes were 0.44 and 0.36 while the FR and CF values were 
from $-1.13 \sim 0.59$ in which the IV and CF values of $600 \sim 900 \mathrm{~m}, 900 \sim 1200 \mathrm{~m}$ and $>1200 \mathrm{~m}$ were all positive as $0.39,0.54$ and $0.59,0.73,0.95$ and 1 respectively. For elevation, the maximum IV, FR and $\mathrm{CF}$ values were found for the class $<4500 \mathrm{~m}$ as $0.52,1.75$ and 0.92 respectively, accounting for $52.61 \%$ of the landslide area. Besides, the minimum value of IV, FR and CF were found for the class $>5500 \mathrm{~m}$ as $-3.1,0.29$ and -0.98 respectively. For plan curvature, the percentages of landslide areas of the classes of $-0.1 \sim 0$ and $0 \sim 0.1$ were $34.09 \%$ and $30.66 \%$, while the IV, FR and CF values were -0.38 and $0.44,1.56$ and 0.81 respectively. For profile curvature, the percentages of landslide areas of the classes of $0.1 \sim 0.2$ was $74.79 \%$ with the IV, FR and CF values of $0.17,1.18$ and 0.35 . Besides, the IV values of the classes of $0.1 \sim 0.2,0.2 \sim 0.3$ and $>0.3$ were the same as 0.59 while 1.8 for FR and 1.18 for CF. For slope angle, the class $<10$ and $10 \sim 20$ had a negative IV and CF values of -3.89 and $-1.27,-0.99$ and -0.85 respectively. While the FR values of these two classes were less than 1 as 0.02 and 0.28 . For the class $20 \sim 30,30 \sim 40$ and $>40$, the IV, FR and CF values were $0.14,1.08$ and $0.95,1.15,2.94$ and $2.59,0.29,0.9$ and 0.98 respectively and are prone to landslide. It can be seen that the TWI class of $0.1 \sim 0.2$ and $0.2 \sim 0.3$ were also prone to landslide. 1.59 and 0.83 with a total $47.4 \%$ of landslide areas. Similarly, landslides were prone to the class $26.21 \%$ of landslide area respectively. The IV, FR and CF values of Shale with siltstone were 0.37 , 1.45 and 0.7 showing obvious contribution towards landslide susceptibility. 
landslide and the conditioning factors in this study, the results of which were basically consistent in predicting the significant and important intervals of each factor.

\subsubsection{Application of integrated models}

The coefficients of generalized linear models reflect the relative importance of variables. The logistic regression equation is as follow:

$\operatorname{logit}(p)=\ln \left(\frac{\mathrm{p}}{1-\mathrm{p}}\right)=0.219+0.519 \times \mathrm{F} 1+0.95 \times \mathrm{F} 2+0.458 \times \mathrm{F} 3+1.307 \times \mathrm{F} 5+0.466 \times F 9$ $\operatorname{logit}(p)=\ln \left(\frac{\mathrm{p}}{1-\mathrm{p}}\right)=-3.592+0.649 \times \mathrm{F} 1+1.39 \times \mathrm{F} 2-0.574 \times \mathrm{F} 3+1.701 \times \mathrm{F} 5+0.637 \times F 9$ $\operatorname{logit}(p)=\ln \left(\frac{\mathrm{p}}{1-\mathrm{p}}\right)=0.897+0.591 \times \mathrm{F} 1+0.942 \times \mathrm{F} 2+1.477 \times \mathrm{F} 5+0.856 \times \mathrm{F} 10$

Where F1 represents the bivariate value of each classification interval in rainfall; F2 represents the bivariate value of each classification interval maximum elevation difference; F5 represents the bivariate value of each classification interval in profile curvature; F3 represents the bivariate value of each classification interval in elevation; F9 represents the bivariate value of each classification interval in distance to fault; F10 represents the IV value of each classification interval in distance to stream.

The integrated models finally selected the factors that have significant influence on the model fitting by rainfall, elevation, maximum elevation difference, profile curvature, distance to fault and distance to stream (Table 3). As for CFLR and FRLR models, both of them involved the factors F1, F2, F3, F5 and F9 and the coefficients of F5 reached the highest as 1.307 and 1.701 respectively. Besides, the coefficient of elevation was positive (0.458) for CFLR model and negative (-0.574) for FRLR model. A negative coefficient means that it is not conducive in the 
occurrence of landslides and was not appropriate for analysis in this study.

As for IVLR model, the coefficients of the selected factors were all positive and the profile curvature reached 1.477 as the highest, which illustrate that it had the highest influence on the occurrence of landslide. The coefficient of rainfall was the smallest as 0.591 , followed by distance to stream as 0.856 and maximum elevation difference as 0.942 . According to the regression coefficient of the selected factors and the IV values of each classification interval, landslides are most likely to occur in areas with profile curvature greater than 0.1 within $2 \mathrm{~km}$ from the stream, maximum elevation difference greater than $1200 \mathrm{~m}$ and rainfall between 440 and $450 \mathrm{~mm}$.

Three integrated models were established in this study to explore the relative importance of conditioning factors, the results of which were obviously different. On the other hand, aspect was not involved in the integrated models while appeared in LR model (Table 3).

\subsection{Landslide susceptibility mapping}

The aforementioned analyses indicated that the IVLR model shows a prominent fitting and generalization capability in predicting the landslide susceptibility compared to the other 3 models presented in this study. Therefore, it is determined as the most suitable model and applied to the calculate the landslide susceptibility index for the whole study area.

The probability $\mathrm{P}$ of the occurrence of landslide in the whole study area was determined based on the four models (LR, CFLR, FRLR and IVLR). The equal spacing principle is used to reclassify the landslide susceptibility index into five levels: very low $(0 \sim 0.2)$, low $(0.2 \sim 0.4)$, moderate (0.4 0.6), high $(0.6 \sim 0.8)$ and very high $(0.8 \sim 1)$.

Fig. 7 show the distribution of landslide susceptible classes and the area percentage of each 
class of each map is summarized in Fig. 8. As for LR model, very low, low, moderate, high or very high susceptible class occupied $27.32 \%, 20.85 \%, 12.55 \%, 21.74 \%$ and $17.53 \%$ of the study area respectively (Fig. 8). In case of CFLR model, the corresponding area percentages were $18.93 \%, 23.27 \%, 17.43 \%, 24.27 \%$ and $16.10 \%$ respectively. Similarly, five reclassified classes of FRLR model accounted for $16.79 \%, 21.08 \%, 21.69 \%, 24.64 \%$ and $15.8 \%$ respectively of the entire area. LSM constructed by IVLR model was also divided into five classes as very low (19.3\%), low (23.8 \%), moderate (15.2\%), high (26.8 \%) and very high (14.9\%). Therefore, the overall differences were obvious among the four models.

A regular landslide susceptibility map should meet two rules: (1) the determined landslide locations should appear in the high or very high-susceptibility class area as much as possible and (2) the very high-susceptibility class area should occupy only a small proportion (Bui et al., 2012). It was noticed that the landslide samples were mainly located in the dark (purple or red) areas and the non-landslide points in the light (green or yellow) areas for IVLR model. Besides, LSM had the smallest percentage of very high susceptible class compared to the others. The very-high susceptibility areas of landslide are mainly distributed around the Yarlung Zangbo river and its tributaries in the study area. River network curves and shapes geomorphology scour eroded slopes in a great extent ${ }^{42}$. The areas near stream were densely populated with human activities and the occurrence of landslide threats lives and property.

The performance of FRLR was also excellent in terms of prediction capability. However, the percentage of moderate susceptible area was the largest among the models as $21.69 \%$. The predicted units as the moderate class were impalpable. Besides, the percentage of low or very low susceptible areas was combinedly smallest as $37.87 \%$ which was contrary to previous research. 


\section{Discussion}

Ensemble algorithms as bagging, stacking and boosting have been applied in LSM and the accuracy was exceeded up to $85 \%$ or $90 \%$ in previous studies ${ }^{43,44}$. New machine learning methods and deep learning emphasize the optimization, and accordingly the multiple parameters involved need to be tuned before application, which is difficult to implement especially for the non-professionals ${ }^{45}$.Traditional statistical methods establish mathematical equations to explore the acceptable. In this study, the IVLR model also performed well with satisfactory prediction capability $(\mathrm{AUC}=0.792$ and accuracy $=78.8 \%)$. Three integrated models performed better than the normal LR model in terms of accuracy, which indicated that the combination was effective. 
the major conditioning factors responsible for landslide occurrence is also important which helps in further engineering guidance. The determination of subjective weight and objective weight helps to distinguish the contribution of these factors and analytic hierarchy process (AHP) and factor analysis (FA) are the two commonly used methods without prior conditions ${ }^{49,50}$. CF, FR and IV are three commonly used bivariate statistical methods which directly reveals the correlation between landslide locations and the influencing factors ${ }^{51,52}$. Besides, factors at different interval range have different susceptibility to landslide, and bivariate methods can distinguish the difference. LR describes the contribution of the conditioning factors through modeling, the coefficients of which reflect the relative importance of different factors and the sign of the coefficients indicate the positive or negative effect of the factors on landslide ${ }^{53}$. Although there is no special requirement for data distribution, the LR model needs to convert nominal variables into dummy variables, which makes the regression model more complex. Therefore, the bivariate and multivariate methods are complementary up to some extent and it is worth combining them for a more reasonable and comprehensive analysis to provide a better way to analyze the major factors in details.

\section{Conclusions}

In the current study, four models based on bivariate and multivariate methods as LR, CFLR, FRLR and IVLR were explored and their performance is compared in LSM in Luoza county and the following conclusions can be drawn:

The IVLR model performed the best in terms of accuracy and the landslide susceptibility map constructed by IVLR model was reasonable and analytical. It indicated that landslides are 
more likely to occur in areas with profile curvature greater than 0.1 , within $2 \mathrm{~km}$ from the stream, maximum elevation difference greater than $1200 \mathrm{~m}$ and rainfall between 440 and $450 \mathrm{~mm}$. The combination of bivariate and multivariate methods not only improves the prediction accuracy but analyze the major conditioning factors in details. It is desirable to improve the advancement of the application by combining multiple methods considering that some methods are complementary up in some ways. The conclusion of the current study is helpful for landslide risk mitigation in highlands and provides idea for non-professionals who fail to optimize the new machine learning methods.

However, there are also some limitations of the present study:

1. There are more possibilities for the combination of different models and further exploration is needed to improve prediction accuracy obviously;

2. Models need to be validated more reliably;

3. The selection of non-landslide locations should be more accurate to improve the purity of samples.

\section{Reference}

1.Das, I., Sahoo, S., Van Westen, C., Stein, A., Hack, R., 2010. Landslide susceptibility assessment using logistic regression and its comparison with a rock mass classification system, along a road section in the northern Himalayas (India). Geomorphology 114, 627-637.

2.Achour Y, BoumezbeurA, Hadji R, Chouabbi A, Cavaleiro V, Bendaoud EA (2017) Landslide susceptibility mapping using analytic hierarchy process and information value methods along a highway road section in Constantine, Algeria. Arab J Geosci 10 (194). https://doi. 
3.Arabameri, A., Pradhan, B., Rezaei, K., Lee, S., Sohrabi, M. An ensemble model for landslide susceptibility mapping in a forested area. Geocarto International, 1-26, 2019.

4.Ni, H. Y., Zheng, W. M., Li, Z. L., Ba, R. J.: Recent catastrophic debris flows in Luding county, SW China: geological hazards, rainfall analysis and dynamic characteristics, Nat. Hazards, 
10.Shortliffe E H, Buchanan B G. A model of inexact reasoning in medicine [J]. Mathematical Biosciences, 1975, 23:351-379.

11.Korup O, Stolle A (2014) Landslide prediction from machine learning. Geol Today 30:26-33.doi:10.1111/gto.12034

12.Chang K-T, Merghadi A, Yunus AP, Pham BT, Dou J. Evaluating scale effects of topographic variables in landslide susceptibility models using GIS-based machine learning techniques. Scientific reports. 2019;9(1):12296. doi:10.1038/s41598-019-48773-2

13.Liang Zhu, Wang Changming, Zhang Zhi-Min and Kaleem-Ullah-Jan Khan. A comparison of statistical and machine learning methods for debris flow susceptibility mapping. Stoch Environ Res Risk Assess (2020b) https://doi.org/10.1007/s00477-020-01851-8

14.Aditian A, Kubota T, Shinohara Y (2018) Comparison of GIS-based landslide susceptibility models using frequency ratio, logistic regression, and artificial neural network in a tertiary region of Ambon, Indonesia. Geomorphology 318: 101-111. https://doi.org/10.1016/j.geomorph.2018.06.006.

15.Liang Zhu, Wang Changming and Kaleem-Ullah-Jan Khan. Application and comparison of different ensemble learning machines combining with a novel sampling strategy for shallow landslide susceptibility mapping. Stoch Environ Res Risk Assess (2020c). https://doi.org/10.1007/s00477-020-01893-y

16.Merghadi, Abdelaziz, Ali P. Yunus, Jie Dou, Jim Whiteley, Binh ThaiPham, Dieu Tien Bui, Ram Avtar, and Boumezbeur Abderrahmane. 2020. Machine Learning Methods for Landslide Susceptibility Studies: A Comparative Overview of Algorithm Performance. Earth-Science Reviews 207 (August): N.PAG. doi:10.1016/j.earscirev.2020.103225. 
17.Youssef AM (2015) Landslide susceptibility delineation in the Ar-Rayth Area, Jizan, Kingdom of Saudi Arabia, by using analytical hierarchy process, frequency ratio, and logistic regression models. Environ Earth Sci. doi:10.1007/s12665-014-4008-9, Article on line first

18.Li, Langping, Hengxing Lan, Changbao Guo, Yongshuang Zhang, Quanwen Li, and Yuming Wu. 2017. A Modified Frequency Ratio Method for Landslide Susceptibility Assessment. Landslides 14 (2): 727-41. doi:10.1007/s10346-016-0771-x.

19.Chen, Z., Liang, S., Ke, Y., Yang, Z., Zhao, H., 2019. Landslide susceptibility assessment using evidential belief function, certainty factor and frequency ratio model at Baxie River basin, NW China. Geocarto International 34, 348-367.

20.Gorsevski P V,Gessler P E,Foltz R B.Spatial prediction of landslide hazard using logistic regression and GIS [J].Transactions in GIS, 2000, 10 ( 3) : 395-415

21.Tian Chunshan, Liu Xilin, Wang Jia. Geohazard susceptibility assessment based on CF model and Logistic regression models in Guangdong[J].HYDROGE \& ENGINEERING, 2016, 43 (06) : 154-161+170

22.Varnes, D.J., 1984. Landslide hazard zonation: a review of principles and practice. Commission on Landslides of the IAEG, UNESCONatural Hazards No. 3 (61 pp.).

23.Kornejady A, Ownegh M, Bahremand A. Landslide susceptibility assessment using maximum entropy model with two different data sampling methods[J]. Catena 2017, 152: 144-162.

24.Van Westen CJ, Castellanos E, Kuriakose SL (2008) Spatial data for landslide susceptibility, hazard, and vulnerability assessment: an overview. Eng Geol 102(3-4):112-131

25.Hong, H., Pradhan, B., Xu, C., Bui, D.T., 2015. Spatial prediction of landslide hazard at the Yihuang area (China) using two-class kernel logistic regression, alternating decision tree and 
support vector machines. Catena 133, 266-281.

26.Maher Ibrahim Sameen,Biswajeet Pradhan,Dieu Tien Bui,Abdullah M. Alamri. Systematic sample subdividing strategy for training landslide susceptibility models[J]. Catena, 2019.

27.Zevenbergen, L.W., Thorne, C.R., 1987. Quantitative analysis of land surface topography. Earth Surf. Proc. land. 12, 47-56.

28.Evans, I.S., 1979. An Integrated System of Terrain Analysis and Slope Mapping. Final Report on Grant DA-ERO-591-73-G0040. University of Durham, England. Freund, Y., Schapire, R.E., 1997. A decision-theoretic generalization of on-line learning and an application to boosting. J. Comput. Syst. Sci. 55, 119-139.

29.Magliulo, P., DiLisio, A., Russo, F., Zelano, A., 2008. Geomorphology and landslide susceptibility assessment using GIS and bivariate statistics: a case study in southern Italy. Nat. Hazards 47, 411-435.

30.Pourghasemi, H.R., Moradi, H.R., Aghda, S.F., 2013. Landslide susceptibility mapping by binary logistic regression, analytical hierarchy process, and statistical index models and assessment of their performances. Nat. Hazards 69, 749-779.

31.Pradhan B (2010) Landslide susceptibility mapping of a catchment area using frequency ratio, fuzzy logic and multivariate logistic regression approaches. J Indian Soc Remote Sens $38(2): 301-320$

32.Carrara, A., Cardinali, M., Detti, R., Guzzetti, F., Pasqui, V., Reichenbach, P., 1991. GIS techniques and statistical models in evaluating landslide hazard. Earth Surf. Process. Landf. 16 (5), 427-445. http://dx.doi.org/10.1002/esp.3290160505.

33.Carrara, A., Cardinali, M., Guzzetti, F., Reichenbach, P., 1995. GIS technology in mapping 
landslide hazard. In: Carrara, A., Guzzetti, F. (Eds.), Geographical Information Systems in Assessing Natural Hazards. Kluwer Academic Publisher, Dordrecht, The Netherlands, pp. $135-175$.

34.Guzzetti, F., Galli, M., Reichenbach, P., Ardizzone, F., Cardinali, M., 2006a. Landslide hazard assessment in the Collazzone area, Umbria, central Italy. Nat. Hazard. Earth Syst. Sci. 6, 115-131. http://dx.doi.org/10.5194/nhess-6-115-2006. Guzzetti, F., Reichenbach, P., Ardizzone, F., Cardinali, M., Galli, M., 2006

35.Hosmer DW, Lemeshow S (1989) Applied regression analysis. Wiley,New York, p 307

36.Atkinson P, Massari R (1998) Generalised linear modelling of susceptibility to landsliding in the central Apennines, Italy. Comput Geosci 24(4):373-385

37.Lee, S., 2005. Application of logistic regression model and its validation for landslide susceptibility mapping using GIS and remote sensing data. Int. J. Remote Sens.26 (7), $1477-1491$.

38.Heckerman, D (1986) Probabilistic interpretations for mycin's certainty factors. Machine Intelligence and Pattern Recognition Vol.4, 167-196.

39.Yin KL, Yan TZ (1988) Statistical prediction model for slope instability of metamorphosed rocks.In:Bonnard, C(ed)Proceedings of the 5th international symposium on landslides, Lausanne Balkema, Rotterdam, pp 1269-1272

40.Korup O, Stolle A (2014) Landslide prediction from machine learning. Geol Today 30:2633. doi:10.1111/gto. 12034

41.Bui DT, Pradhan B, Lofman O, Revhaug I, Dick OB (2012) Landslide susceptibility assessment in the Hoa Binh Province of Vietnam: a comparison of the Levenberg-Marquardt 
and Bayesian regularized neural networks. Geomorphology. doi:10.1016/j.geomorph.2012.04.023

42.Pourghasemi, H.R., Mohammady, M., Pradhan, B., 2012. Landslide susceptibility mapping using index of entropy and conditional probability models in GIS: Safarood Basin, Iran. Catena 97, 71-84.

43.Chen Wei, Li Yang. GIS-based evaluation of landslide susceptibility using hybrid computational intelligence models. 2020, 195.

44.Dou, J., Yunus, A.P., Bui, D.T. et al. Improved landslide assessment using support vector machine with bagging, boosting, and stacking ensemble machine learning framework in a mountainous watershed, Japan. Landslides 17, 641-658 (2020).

45.Pourghasemi, H. R., Kariminejad, N., Amiri, M., Edalat, M., Zarafshar, M., Blaschke, T., \& Cerda, A. (2020). Assessing and mapping multi-hazard risk susceptibility using a machine learning technique. Scientific $\quad$ Reports, $10(1), \quad$ 1-9. https://doi.org/10.1038/s41598-020-60191-3

46.Franny G. MURILLO-GARCíA, Stefan STEGER, Irasema ALCáNTARA-AYALA.Landslide susceptibility: a statistically-based assessment on a depositional pyroclastic ramp[J].Journal of Mountain Science, 2019 ,16(03):561-580. DOI: 10.1007/s11629-018-5225-6

47.Zhang Yi-xing,Lan Heng-xing, Li Lang-ping,Wu Yu-ming,Chen Jun-hui, Tian Nai-man. Optimizing the frequency ratio method for landslide susceptibility assessment: A case study of the Caiyuan Basin in the southeast mountainous area of China[J].Journal of Mountain Science,2020,17(02):340-357.

48.Chen T, Niu R, Jia X (2016) A comparison of information value and logistic regression models 
in landslide susceptibility mapping by using GIS. Environmental Earth Sciences 75(10): 1-16.

$$
\text { DOI: } 10.1007 / \mathrm{s} 12665-016-5317-\mathrm{y}
$$

49.Mandal B, Mandal S. Analytical hierarchy process (AHP) based landslide susceptibility mapping of Lish river basin of eastern Darjeeling Himalaya, India. Advances in Space Research. 2018;62(11):3114-3132. doi:10.1016/j.asr.2018.08.008

50.Tang Yaming, Feng Fan, Guo Zizheng, Feng Wei, Li Zhengguo, Wang Jiayun, Sun Qiaoyin, Ma Hongna, Li Yane. Integrating principal component analysis with statistically-based models for analysis of causal factors and landslide susceptibility mapping: A comparative study from the loess plateau area in Shanxi (China)[J]. Journal of Cleaner Production, 2020, 277.

51.Korup O, Stolle A (2014) Landslide prediction from machine learning. Geology Today 30(1): 26-33. http://doi.org/10.1111/gto.12034

52.Tay LT, Lateh H, Hossain MK, Kamil AA (2014) Landslide hazard mapping using a poisson distribution: a case study in Penang Island, Malaysia. In Landslide Science for a Safer Geoenvironment (pp.521-525). Springer International Publishing

53.Pourghasemi HR, Moradi HR, Aghda SMF. (2013) Landslide susceptibility mapping by binary logistic regression, analytical hierarchy process, and statistical index models and assessment of their performances. Natural hazards 69(1): 749-779. DOI: 10.1007/s11069-013-0728-5

\section{Acknowledgements}

This work was supported by the National Natural Science Foundation of China (Grant No.

41972267, 41977221, and 41572257 ). 


\section{Author contributions}

$550 \mathrm{Han} \mathrm{Hu}$ and Zhu Liang were responsible for modeling and writing manuscript. Changming Wang

551 was responsible for the review.

\section{Competing interests}

553 The authors declare no competing interests.

554 Table 1 Spatial relationship between landslide conditioning factors and landslides

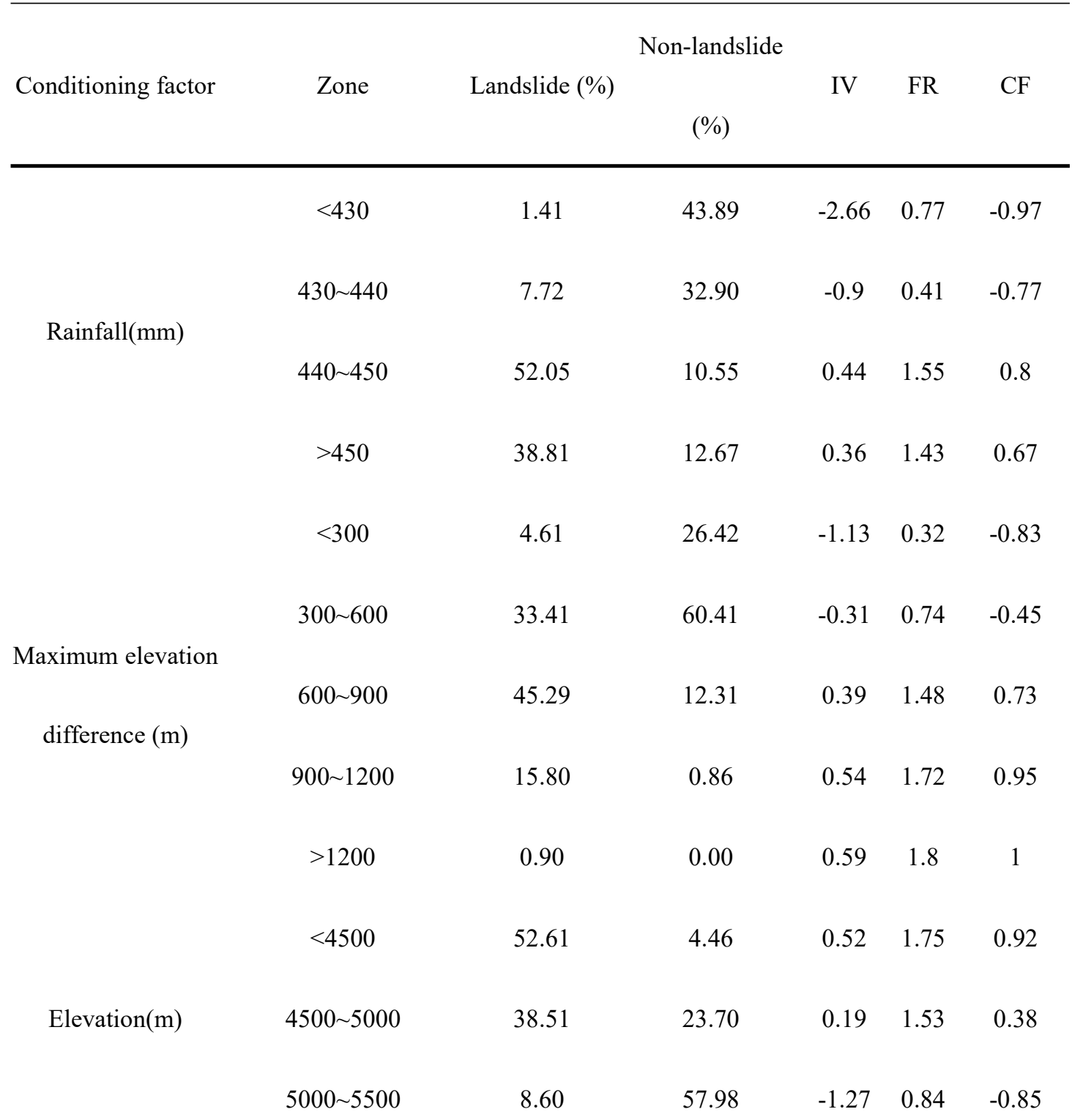




\begin{tabular}{|c|c|c|c|c|c|c|}
\hline & $>5500$ & 0.28 & 13.85 & -3.1 & 0.29 & -0.98 \\
\hline & $<-0.1$ & 7.35 & 1.64 & 0.42 & 1.53 & 0.78 \\
\hline & $-0.1 \sim 0$ & 34.09 & 69.61 & -0.38 & 0.68 & -0.51 \\
\hline & $0 \sim 0.1$ & 30.66 & 5.91 & 0.44 & 1.56 & 0.81 \\
\hline Plan curvature & & & & & & \\
\hline & $0.1 \sim 0.2$ & 5.08 & 0.06 & 0.58 & 1.78 & 0.99 \\
\hline & $0.2 \sim 0.3$ & 0.01 & 1.12 & -4.54 & 0.01 & -1 \\
\hline & $>0.3$ & 0.24 & 0.17 & 0.14 & 1.15 & 0.29 \\
\hline & $<0$ & 9.03 & 51.19 & -1.12 & 0.33 & -0.82 \\
\hline & $0 \sim 0.1$ & 74.79 & 48.81 & 0.17 & 1.18 & 0.35 \\
\hline Profile curvature & $0.1 \sim 0.2$ & 13.76 & 0.00 & 0.59 & 1.8 & 1 \\
\hline & $0.2 \sim 0.3$ & 1.33 & 0.00 & 0.59 & 1.8 & 1 \\
\hline & $>0.3$ & 1.08 & 0.00 & 0.59 & 1.8 & 1 \\
\hline & $<10$ & 0.09 & 9.44 & -3.89 & 0.02 & -0.99 \\
\hline & $10 \sim 20$ & 6.32 & 42.83 & -1.27 & 0.28 & -0.85 \\
\hline Slope angle $\left(^{\circ}\right)$ & $20 \sim 30$ & 62.50 & 44.52 & 0.14 & 1.15 & 0.29 \\
\hline & $30 \sim 40$ & 22.52 & -10.95 & 1.08 & 2.94 & 0.9 \\
\hline & $>40$ & 1.91 & -0.73 & 0.95 & 2.59 & 0.98 \\
\hline & $<0$ & 0.01 & 0.06 & -0.82 & 0.50 & -0.66 \\
\hline & $0 \sim 0.1$ & 0.14 & 0.25 & -0.28 & 0.86 & -0.25 \\
\hline TWI & & & & & & \\
\hline & $0.1 \sim 0.2$ & 0.39 & 0.26 & 0.16 & 1.33 & 0.49 \\
\hline & $0.2 \sim 0.3$ & 0.25 & 0.20 & 0.09 & 1.24 & 0.38 \\
\hline
\end{tabular}




\begin{tabular}{|c|c|c|c|c|c|c|}
\hline & $0.3 \sim 0.4$ & 0.10 & 0.14 & -0.18 & 0.95 & -0.09 \\
\hline & $>0.4$ & 0.11 & 0.09 & 0.08 & 1.23 & 0.37 \\
\hline & $<2000$ & 47.40 & 7.97 & 0.46 & 1.59 & 0.83 \\
\hline & $2000 \sim 4000$ & 25.17 & 11.87 & 0.27 & 1.31 & 0.53 \\
\hline Distance to & $4000 \sim 6000$ & 15.09 & 14.04 & 0.03 & 1.03 & 0.07 \\
\hline \multirow[t]{5}{*}{$\operatorname{road}(\mathrm{m})$} & $6000 \sim 8000$ & 5.83 & 14.40 & -0.5 & 0.6 & -0.6 \\
\hline & $8000 \sim 10000$ & 3.22 & 12.63 & -0.83 & 0.44 & -0.74 \\
\hline & $>10000$ & 3.19 & 39.21 & -1.79 & 0.17 & -0.92 \\
\hline & $<2000$ & 48.10 & 10.97 & 0.42 & 1.52 & 0.77 \\
\hline & $2000 \sim 4000$ & 28.91 & 13.73 & 0.27 & 1.3 & 0.52 \\
\hline Distance to & $4000 \sim 6000$ & 14.56 & 17.27 & -0.08 & 0.92 & -0.16 \\
\hline \multirow[t]{5}{*}{ fault (m) } & $6000 \sim 8000$ & 6.04 & 26.93 & -0.93 & 0.39 & -0.78 \\
\hline & $8000 \sim 10000$ & 1.40 & 15.98 & -1.73 & 0.18 & -0.91 \\
\hline & $>10000$ & 1.00 & 15.12 & -1.99 & 0.14 & -0.93 \\
\hline & $<2000$ & 65.88 & 36.35 & 0.22 & 1.25 & 0.45 \\
\hline & $2000 \sim 4000$ & 22.58 & 28.34 & -0.11 & 0.9 & -0.2 \\
\hline Distance to stream & $4000 \sim 6000$ & 7.52 & 17.96 & -0.48 & 0.62 & -0.58 \\
\hline \multirow[t]{3}{*}{$(\mathrm{m})$} & $6000 \sim 8000$ & 2.11 & 9.31 & -0.92 & 0.4 & -0.77 \\
\hline & $8000 \sim 10000$ & 1.90 & 5.24 & -0.58 & 0.56 & -0.64 \\
\hline & $>10000$ & 0.30 & 2.43 & -1.43 & 0.24 & -0.88 \\
\hline Aspect & North (A1) & 0.81 & 0.02 & 0.57 & 1.77 & 0.98 \\
\hline
\end{tabular}




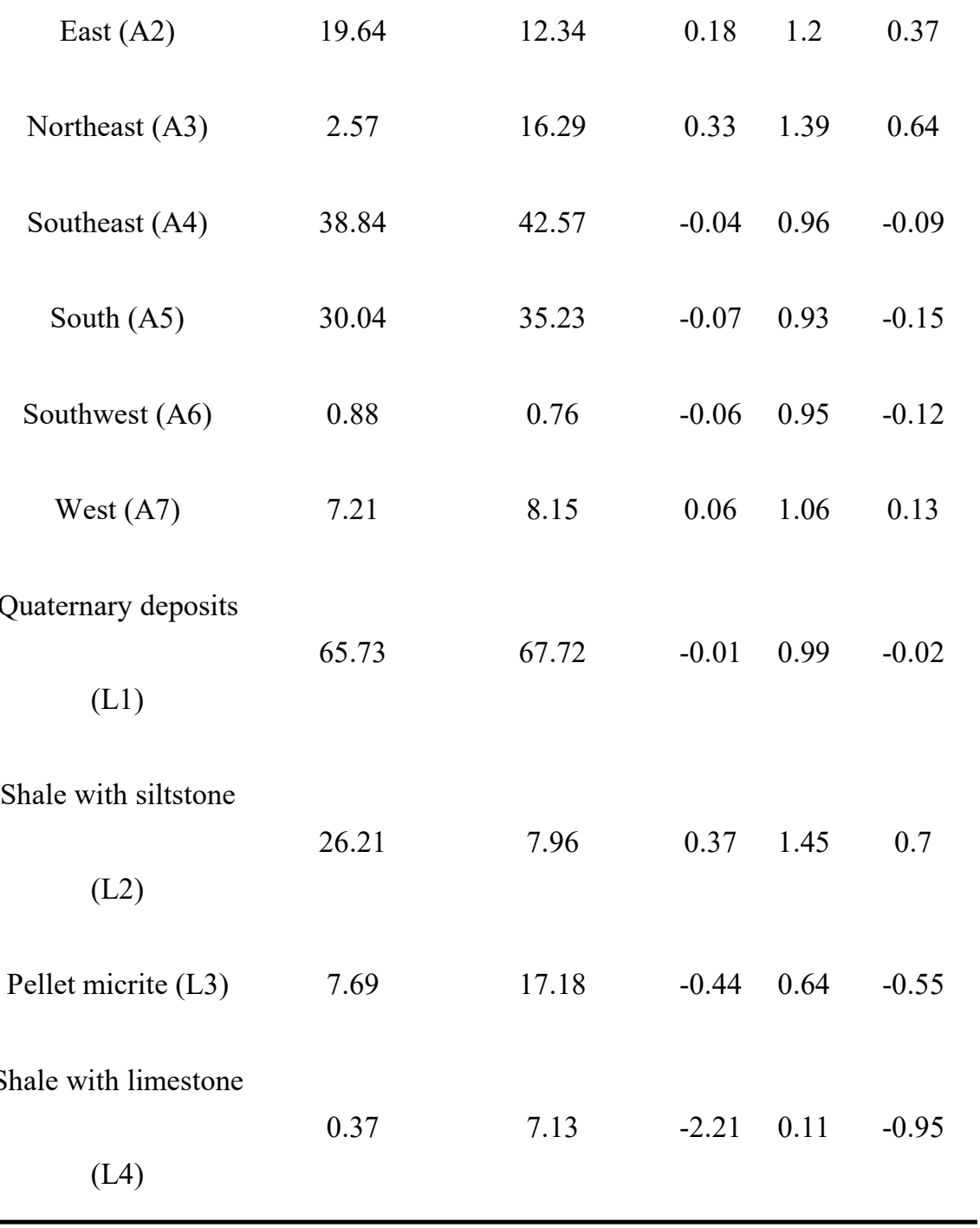

Table 2 Multicollinearity diagnosis indexes for variables

\begin{tabular}{cc}
\hline Variables & VIF \\
Rainfall & 2.645 \\
\hline Maximum elevation difference & 1.668 \\
Elevation & 4.346 \\
Plan curvature & 1.058 \\
& \\
Profile curvature & 0.03 \\
Slope angle & 1.952
\end{tabular}


Table 3 Coefficients of the logistic regression models

\begin{tabular}{|c|c|c|c|c|}
\hline Parameters/coefficients & LR & CFLR & FRLR & IVLR \\
\hline Rainfall & 0 & 0.519 & 0.649 & 0.591 \\
\hline \multicolumn{5}{|l|}{ Maximum elevation } \\
\hline & 0.861 & 0.95 & 1.39 & 0.942 \\
\hline \multicolumn{5}{|l|}{ difference } \\
\hline Elevation & 0.542 & 0.458 & -0.574 & 0 \\
\hline Plan curvature & -3.19 & 0 & 0 & 1.477 \\
\hline Profile curvature & 0.982 & 1.307 & 1.701 & 0 \\
\hline Slope angle & 0 & 0 & 0 & 0 \\
\hline TWI & 0 & 0 & 0 & 0 \\
\hline Distance to road & 0 & 0 & 0 & 0 \\
\hline Distance to fault & -0.396 & 0.466 & 0.637 & 0 \\
\hline Distance to stream & 0 & 0 & 0 & 0.856 \\
\hline Lithology & 0 & 0 & 0 & 0 \\
\hline Aspect & & 0 & 0 & 0 \\
\hline A1 & -23.616 & & & \\
\hline A2 & 0.152 & & & \\
\hline
\end{tabular}




\begin{tabular}{cllll} 
A3 & 1.158 & & \\
A4 & 0.493 & & & \\
A5 & 0.551 & & & \\
A6 & -0.057 & & & \\
& & & & \\
Constant & -0.453 & 0.219 & -3.592 & 0.897 \\
\hline
\end{tabular}

557 Table 4 Statistics of the logistic regression models

\begin{tabular}{ccccc}
\hline & LR & CFLR & FRLR & IVLR \\
\hline-2 Log likelihood & 51.099 & 61.851 & 63.044 & 74.598 \\
Cox \& Snell R ${ }^{2}$ & 0.577 & 0.633 & 0.662 & 0.672 \\
Nagelkerke R ${ }^{2}$ & 0.503 & 0.744 & 0.682 & 0.695 \\
\hline
\end{tabular}

558 Table 5 Models' performance using training dataset

\begin{tabular}{ccccc}
\hline Indexes & LR & CFLR & FRLR & IVLR \\
\hline TP (\%) & 83.4 & 82.6 & 84.6 & 81.0 \\
TN (\%) & 71.3 & 74.9 & 80.2 & 84.2 \\
FP (\%) & 16.6 & 17.4 & 15.4 & 19.0 \\
FN (\%) & 28.7 & 25.1 & 19.8 & 15.8 \\
Sensitivity (\%) & 74.2 & 76.8 & 80.9 & 81.6 \\
Specificity (\%) & 80.7 & 81.5 & 84.2 & 83.5 \\
Accuracy (\%) & 77.3 & 78.7 & 82.4 & 82.6 \\
\hline
\end{tabular}

559 Table 6 ROC analysis of the three models using training data.

\begin{tabular}{|c|c|c|c|}
\hline Models & AUC & Standard Error & $95 \%$ Confidence Interval \\
\hline
\end{tabular}




$\begin{array}{cccc}\text { LR } & 0.781 & 0.021 & 0.736-0.882 \\ \text { CFLR } & 0.800 & 0.021 & 0.760-0.841 \\ \text { FRLR } & 0.820 & 0.020 & 0.781-0.860 \\ \text { IVLR } & 0.829 & 0.019 & 0.791-0.867\end{array}$

560 Table 7 Models' performance using verification dataset

\begin{tabular}{ccccc}
\hline Indexes & LR & CFLR & FRLR & IVLR \\
\hline TP (\%) & 76.9 & 83.1 & 79.4 & 82.5 \\
TN (\%) & 72.5 & 71.0 & 76.8 & 75.4 \\
FP (\%) & 23.1 & 16.9 & 20.6 & 17.5 \\
FN (\%) & 27.5 & 29.0 & 23.2 & 24.6 \\
Sensitivity (\%) & 73.3 & 74.1 & 77.5 & 76.8 \\
Specificity (\%) & 75.9 & 80.7 & 78.5 & 81.6 \\
Accuracy (\%) & 74.6 & 76.9 & 78.0 & 78.8 \\
\hline
\end{tabular}

561 Table 8 ROC analysis of the three models using verification data.

\begin{tabular}{cccc}
\hline Models & AUC & Standard Error & $95 \%$ Confidence Interval \\
\hline LR & 0.720 & 0.046 & $0.629-0.810$ \\
CFLR & 0.757 & 0.043 & $0.672-0.842$ \\
FRLR & 0.766 & 0.043 & $0.682-0.852$ \\
IVLR & 0.792 & 0.041 & $0.712-0.872$ \\
\hline
\end{tabular}




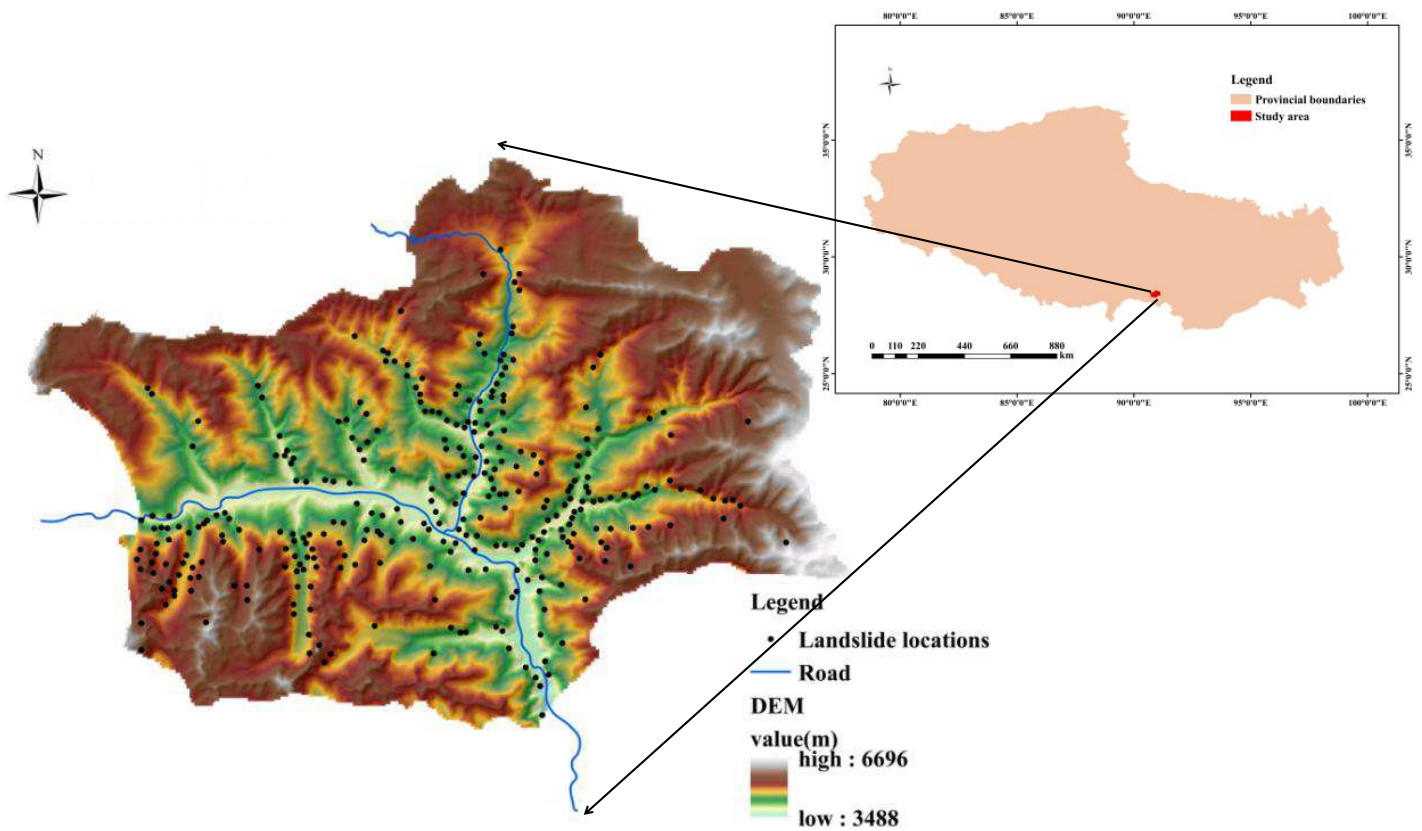

563 Fig. 1. Location map of the study area showing landslide inventory.

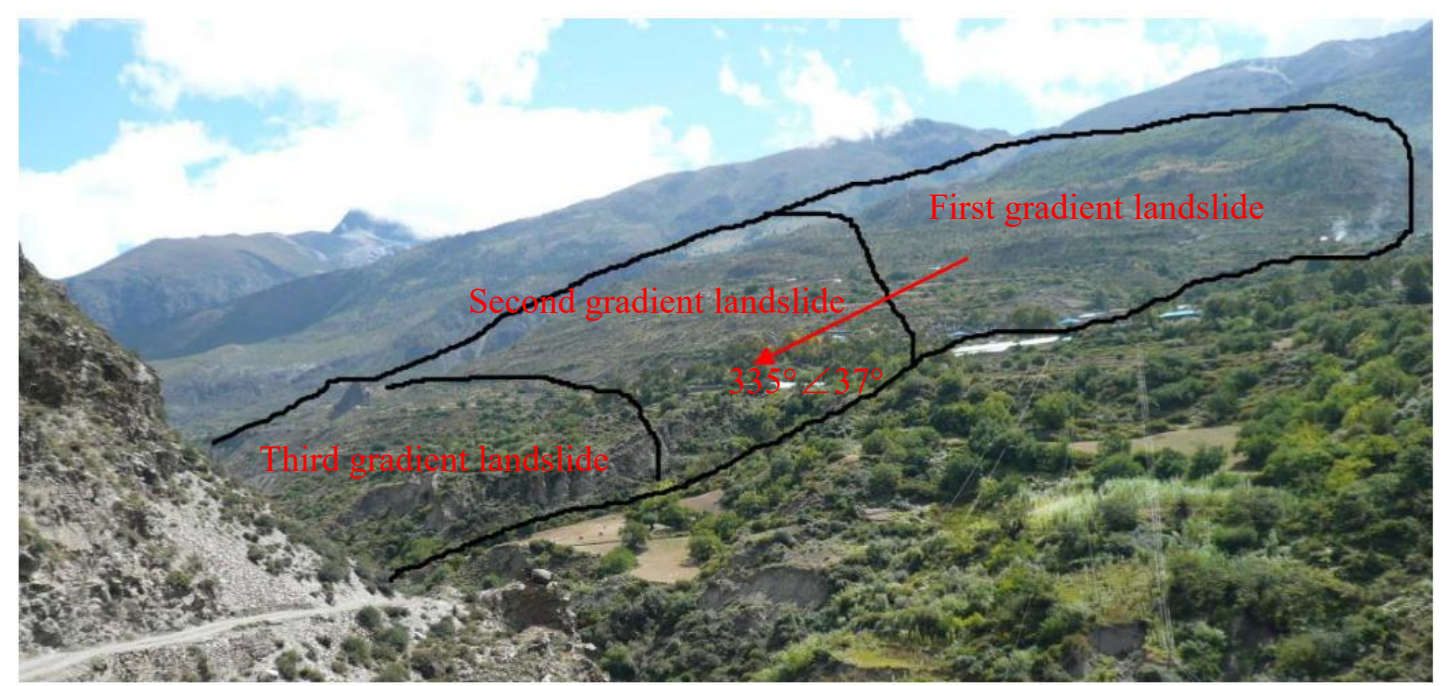

Fig. 2. Multistage landslide in Lakang county.
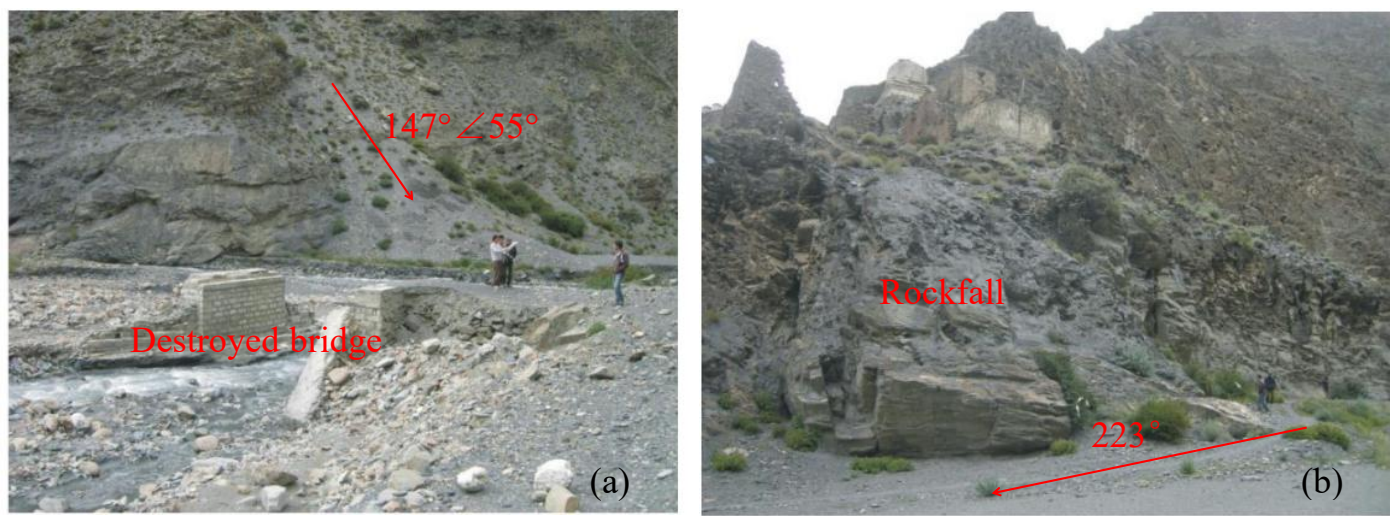

567 Fig. 3. Multistage landslide in Degacuo village. 

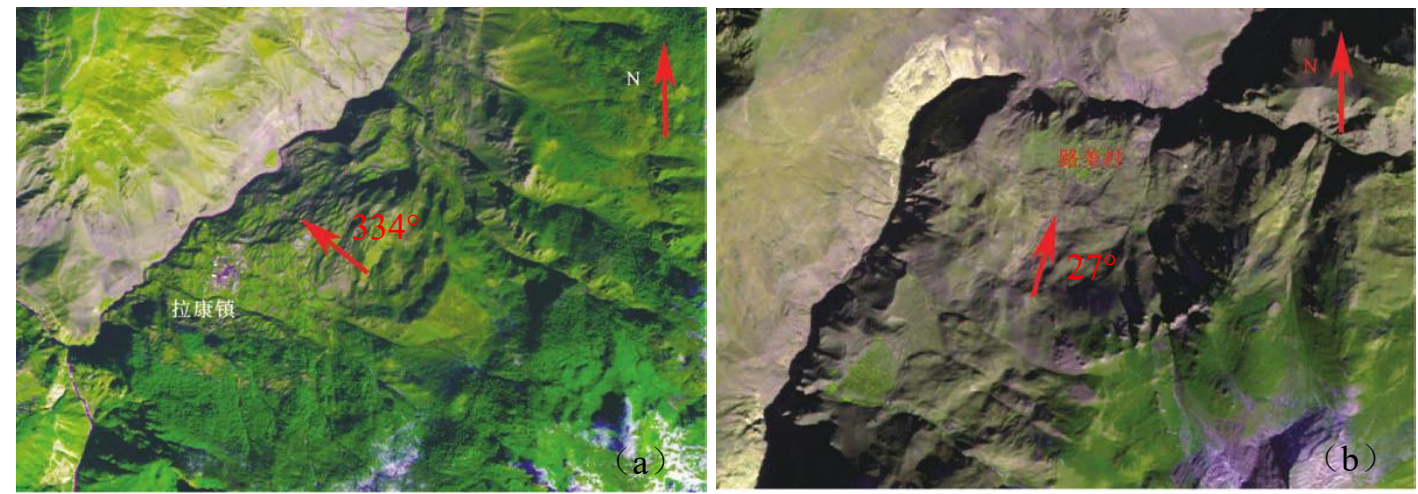

Fig.4. Stereo remote sensing map of landslides in Luoza county (Tong et al., 2019): (a) Landslide in

570 Lakang county; (b) Landslide in Lumei village.

571

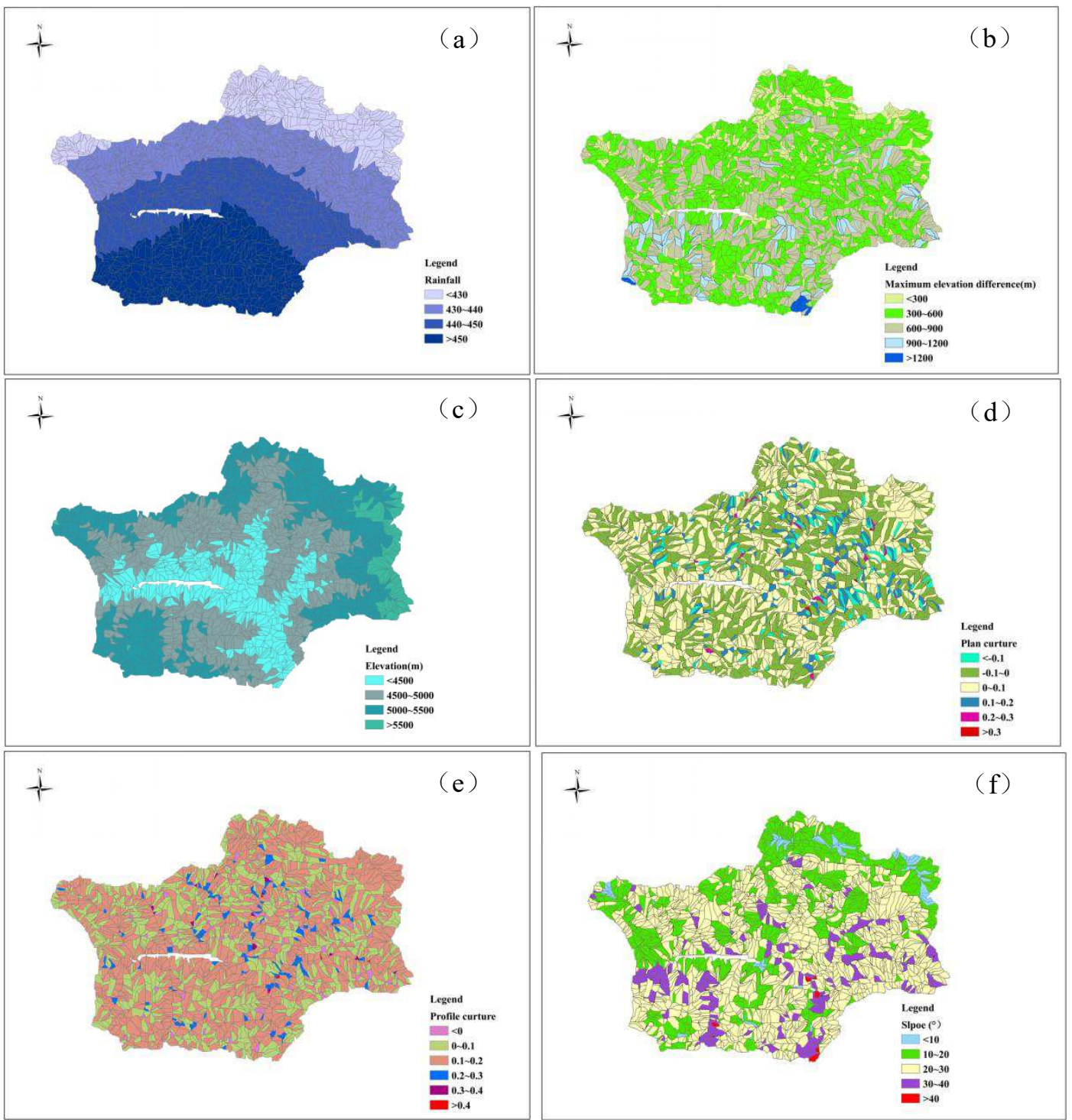




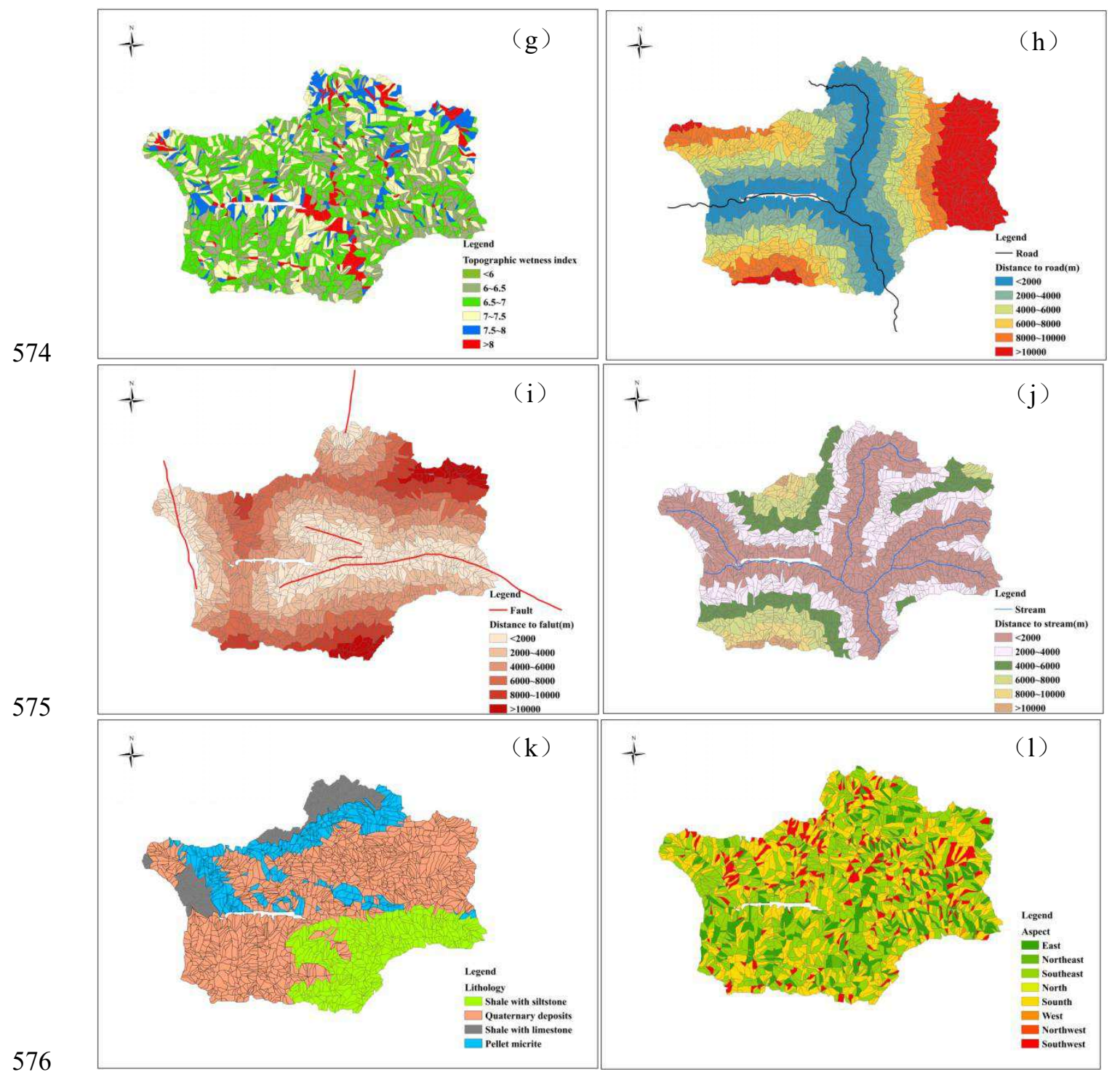

577 Fig.5. Study area thematic maps: (a ) Rainfall; (b ) MED Slope angle DTR; (c) Altitude aspect;

578 (d) Plan curvature; (e) Profile curvature;（f) Slope;（g）TWI;（h）DTR;（i ) DTF;（j) DTS;

579 (k) Lithology; (1) Slope aspect. 

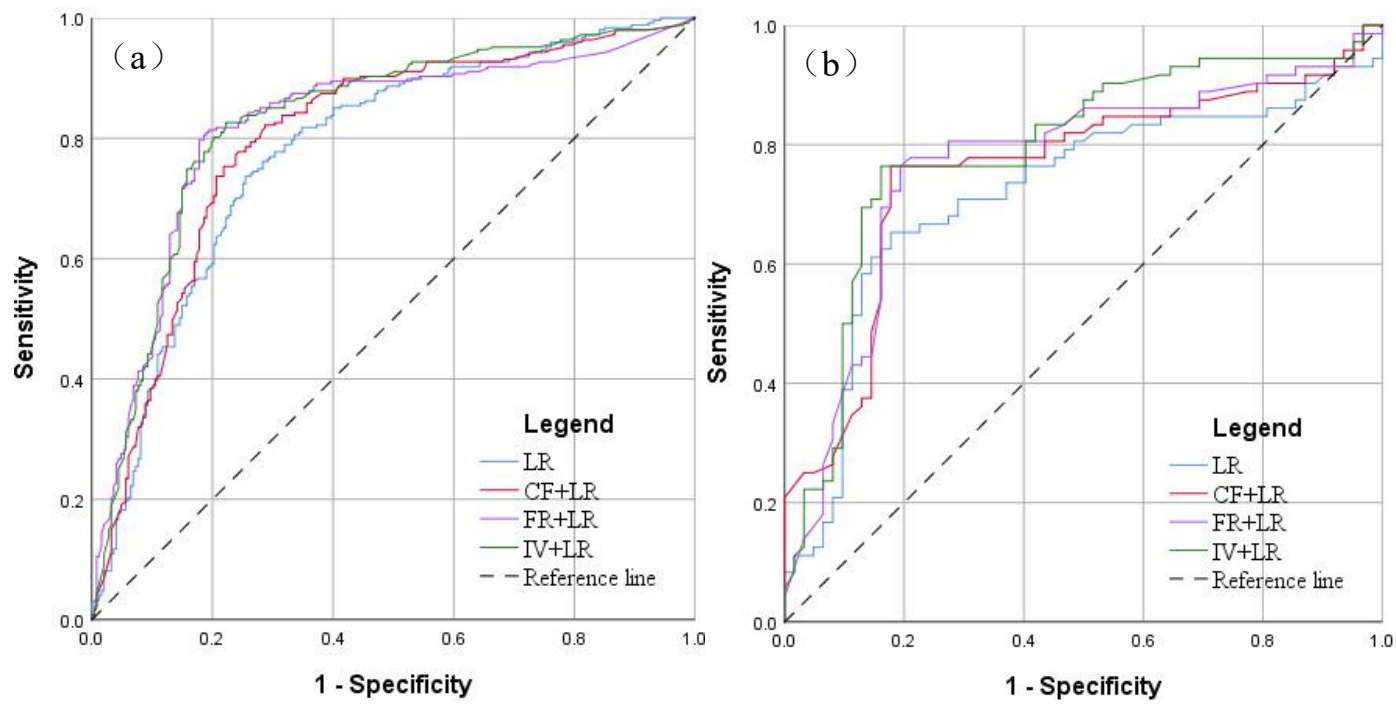

Fig.6. Analysis of ROC curve for the landslide susceptibility map: (a) Success rate curve of

582 landslide using the training dataset; (b) Prediction rate curve of landslide using the validation

583 dataset.
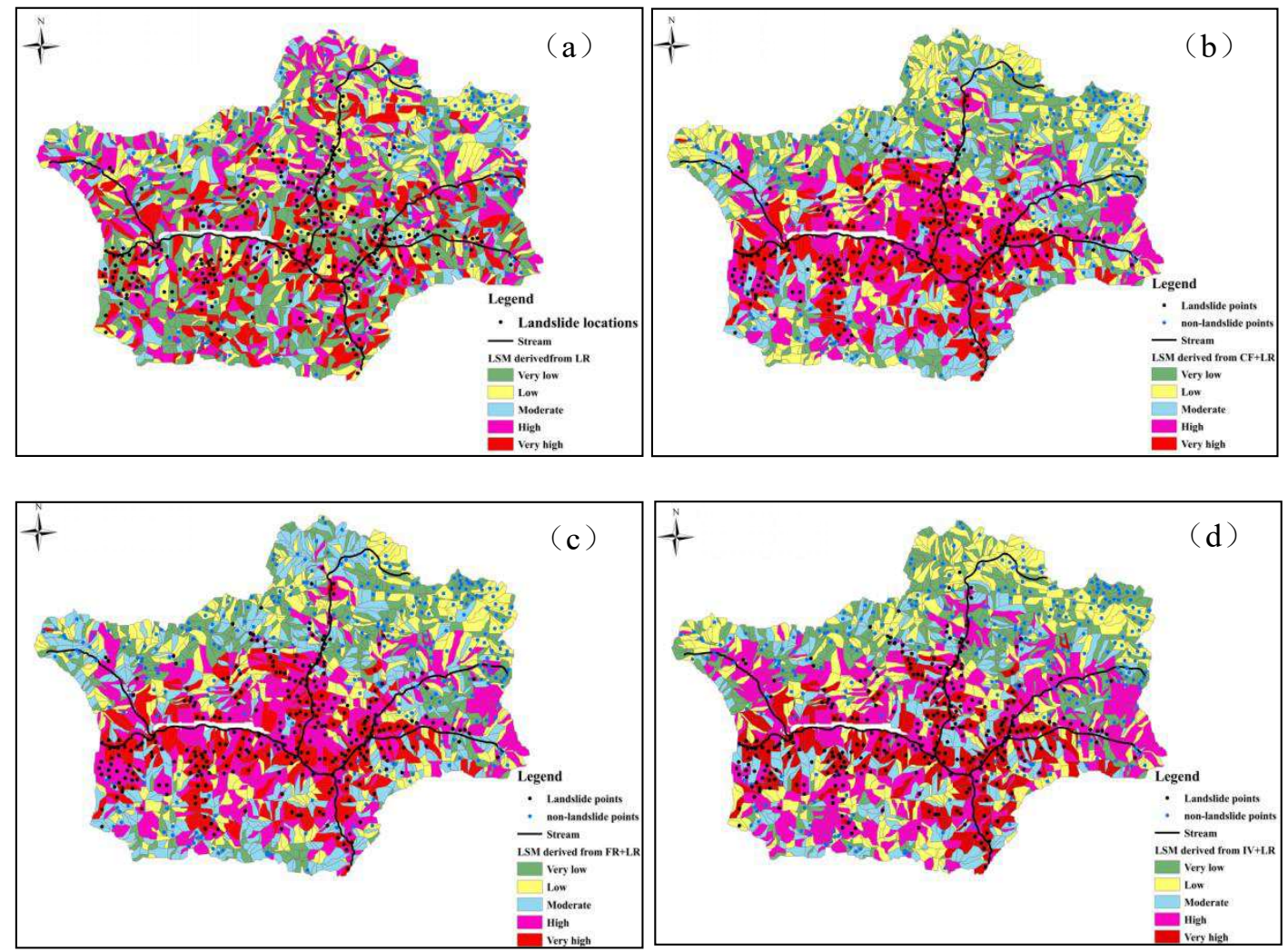

Fig. 7 Landslide susceptibility maps: (a) LR model; (b) CFLR model; (c) FRLR model; (d) IVLR

model. 


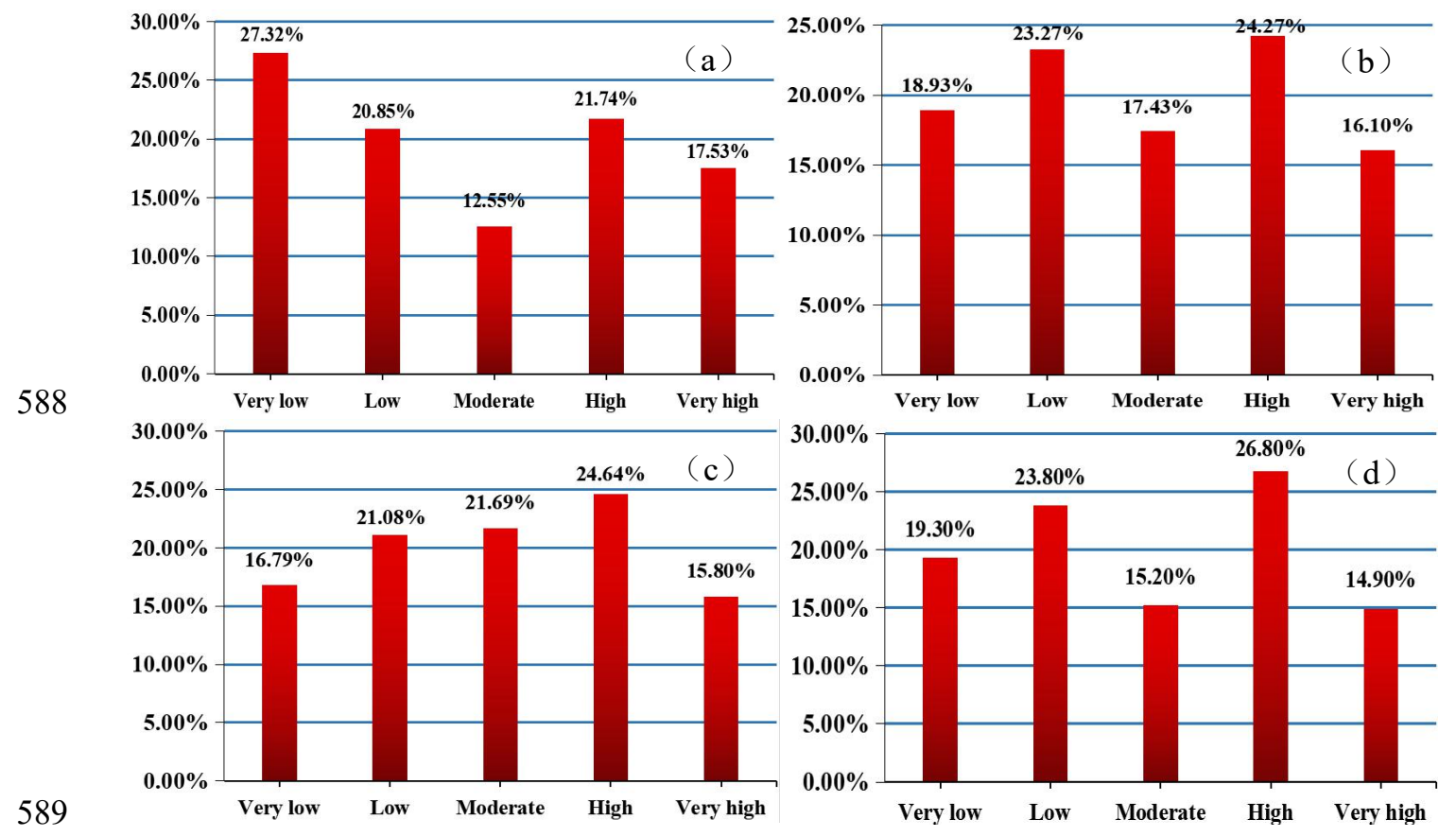

Fig.8. Percentages of areas in different susceptibility classes for landslide: (a) LR model; (b) 


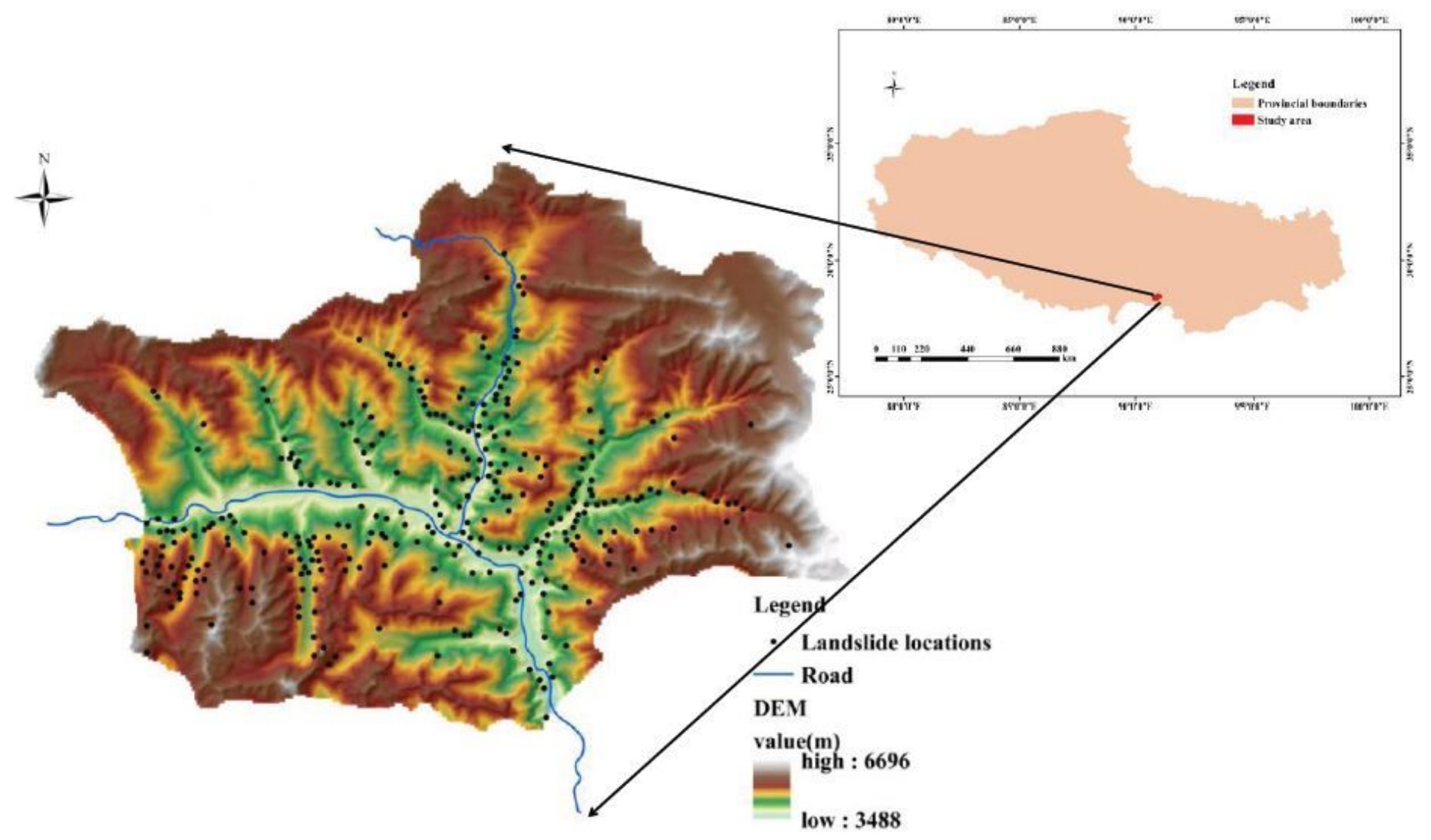

Figure 1

Location map of the study area showing landslide inventory. Note: The designations employed and the presentation of the material on this map do not imply the expression of any opinion whatsoever on the part of Research Square concerning the legal status of any country, territory, city or area or of its authorities, or concerning the delimitation of its frontiers or boundaries. This map has been provided by the authors. 


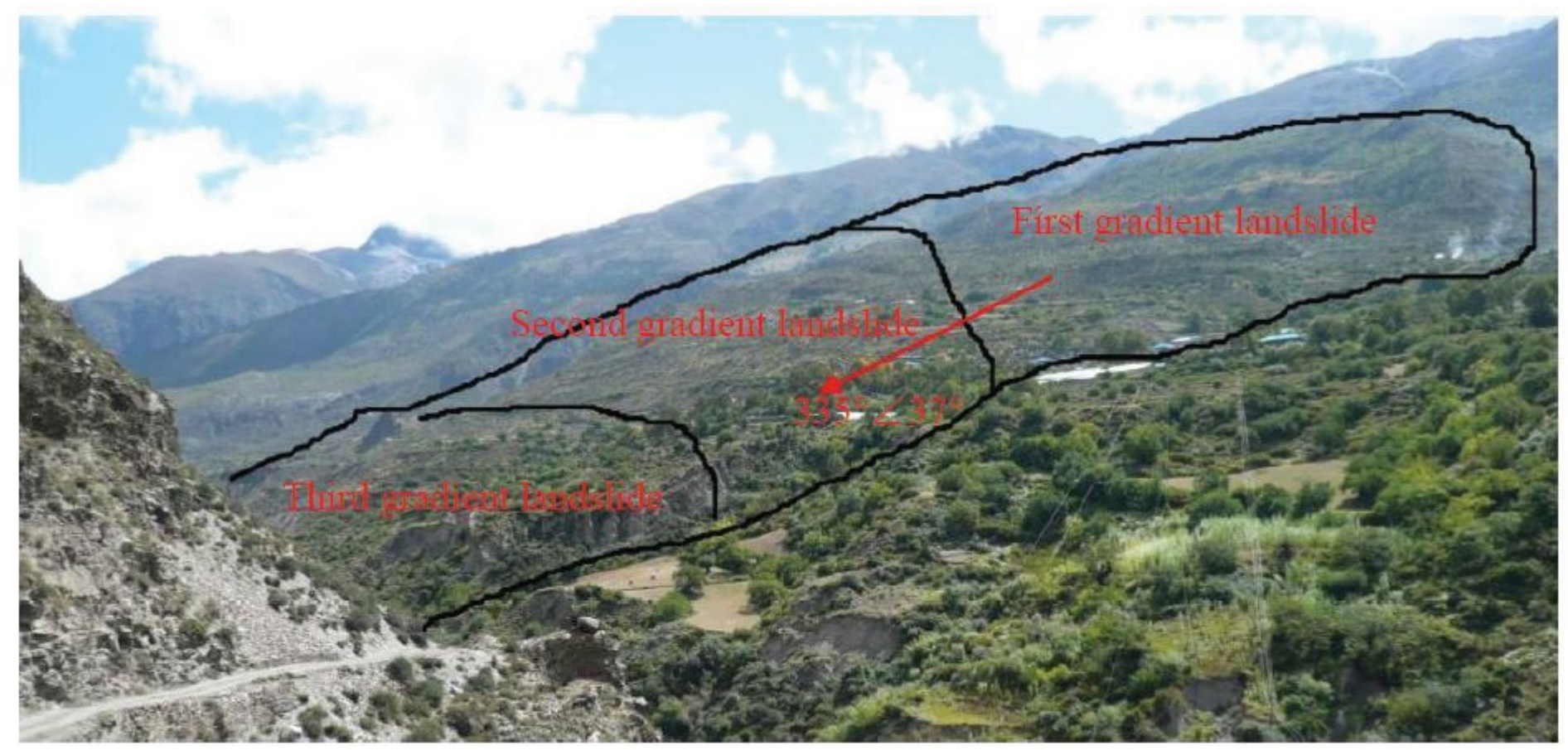

\section{Figure 2}

Multistage landslide in Lakang county. Note: The designations employed and the presentation of the material on this map do not imply the expression of any opinion whatsoever on the part of Research Square concerning the legal status of any country, territory, city or area or of its authorities, or concerning the delimitation of its frontiers or boundaries. This map has been provided by the authors.
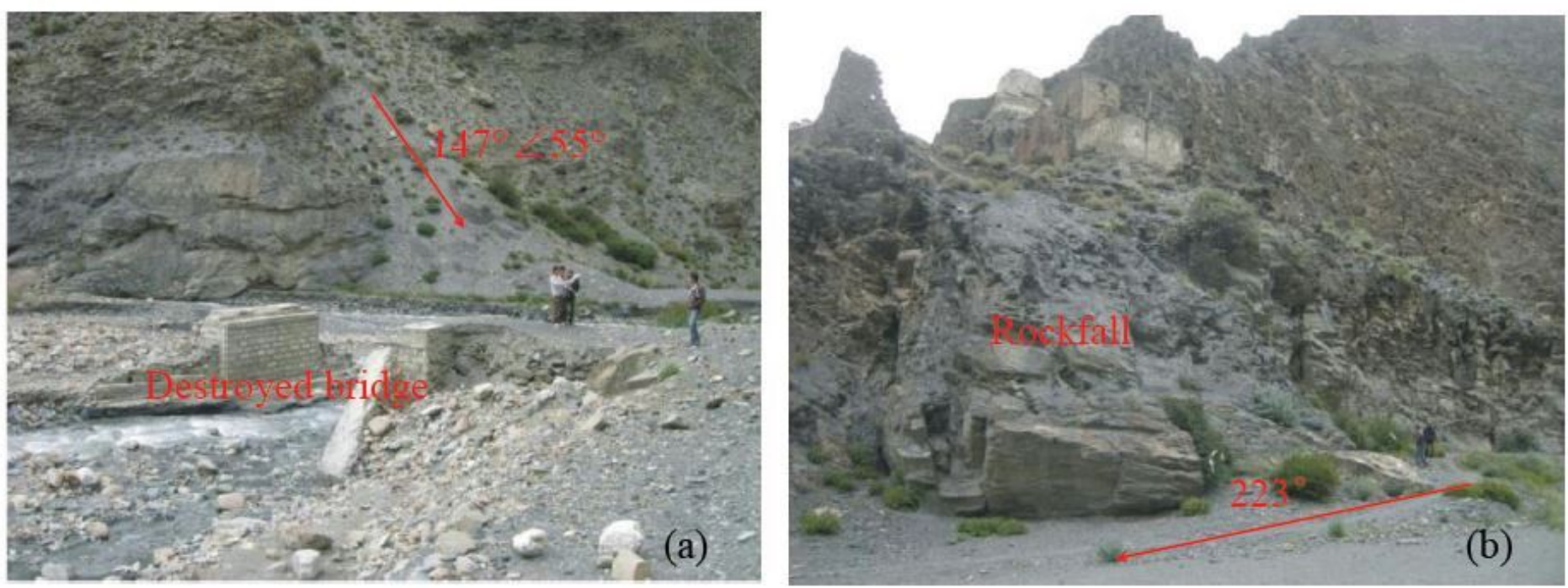

\section{Figure 3}

Multistage landslide in Degacuo village. Note: The designations employed and the presentation of the material on this map do not imply the expression of any opinion whatsoever on the part of Research 
Square concerning the legal status of any country, territory, city or area or of its authorities, or concerning the delimitation of its frontiers or boundaries. This map has been provided by the authors.
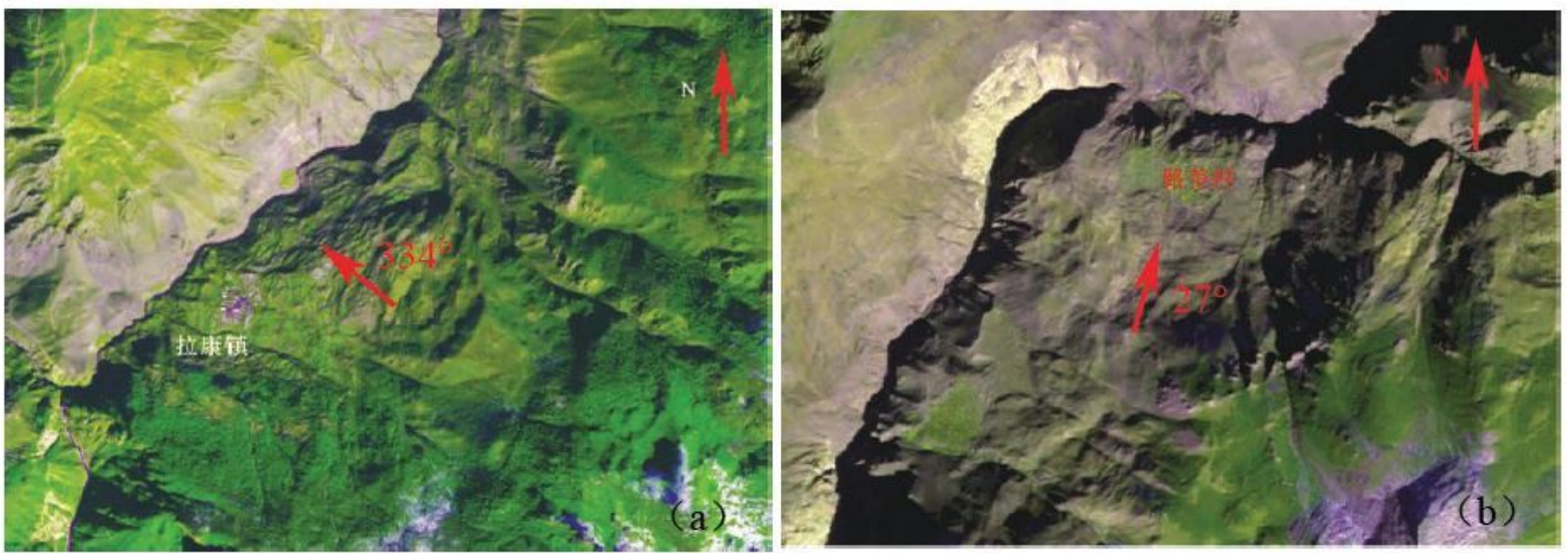

\section{Figure 4}

Stereo remote sensing map of landslides in Luoza county (Tong et al., 2019): (a) Landslide in Lakang county; (b) Landslide in Lumei village. Note: The designations employed and the presentation of the material on this map do not imply the expression of any opinion whatsoever on the part of Research Square concerning the legal status of any country, territory, city or area or of its authorities, or concerning the delimitation of its frontiers or boundaries. This map has been provided by the authors.

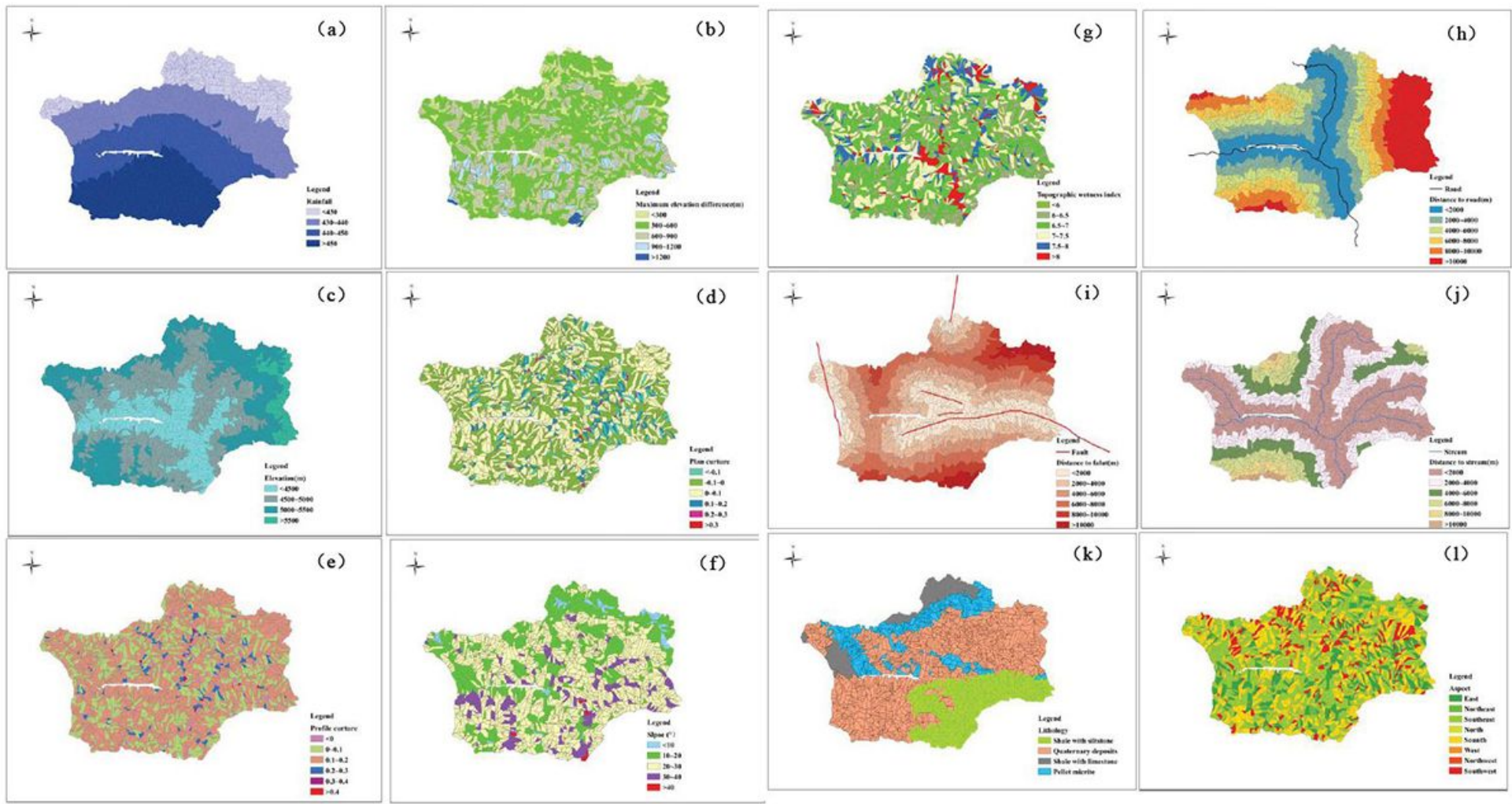




\section{Figure 5}

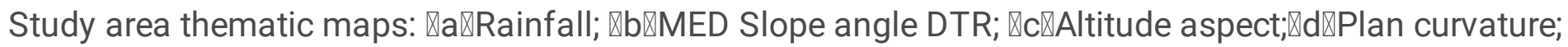

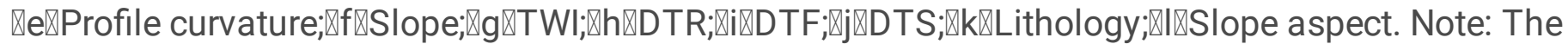
designations employed and the presentation of the material on this map do not imply the expression of any opinion whatsoever on the part of Research Square concerning the legal status of any country, territory, city or area or of its authorities, or concerning the delimitation of its frontiers or boundaries. This map has been provided by the authors.
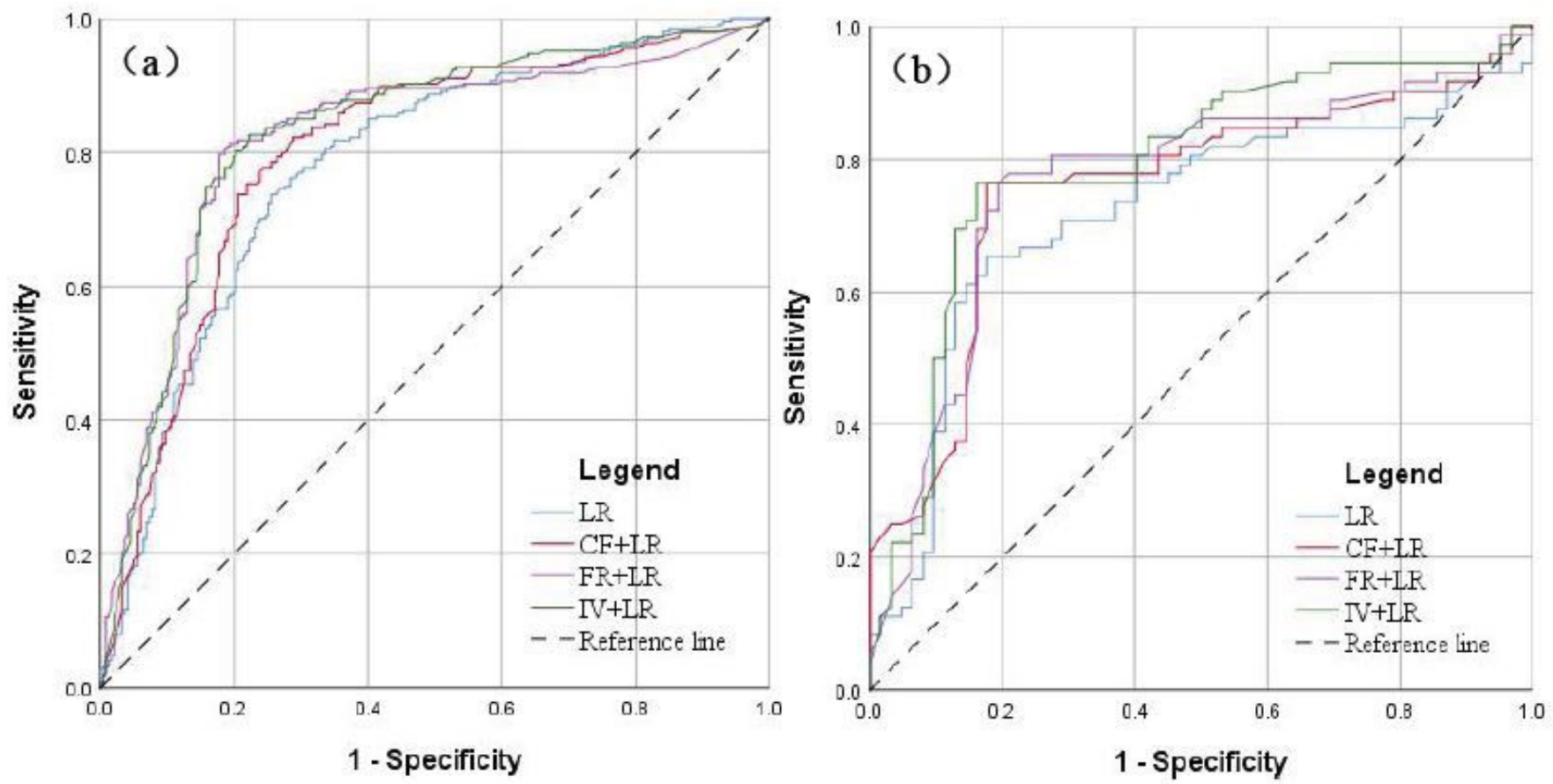

Figure 6

Analysis of ROC curve for the landslide susceptibility map: (581 a) Success rate curve of landslide using the training dataset; (b) Prediction rate curve of landslide using the validation dataset. 

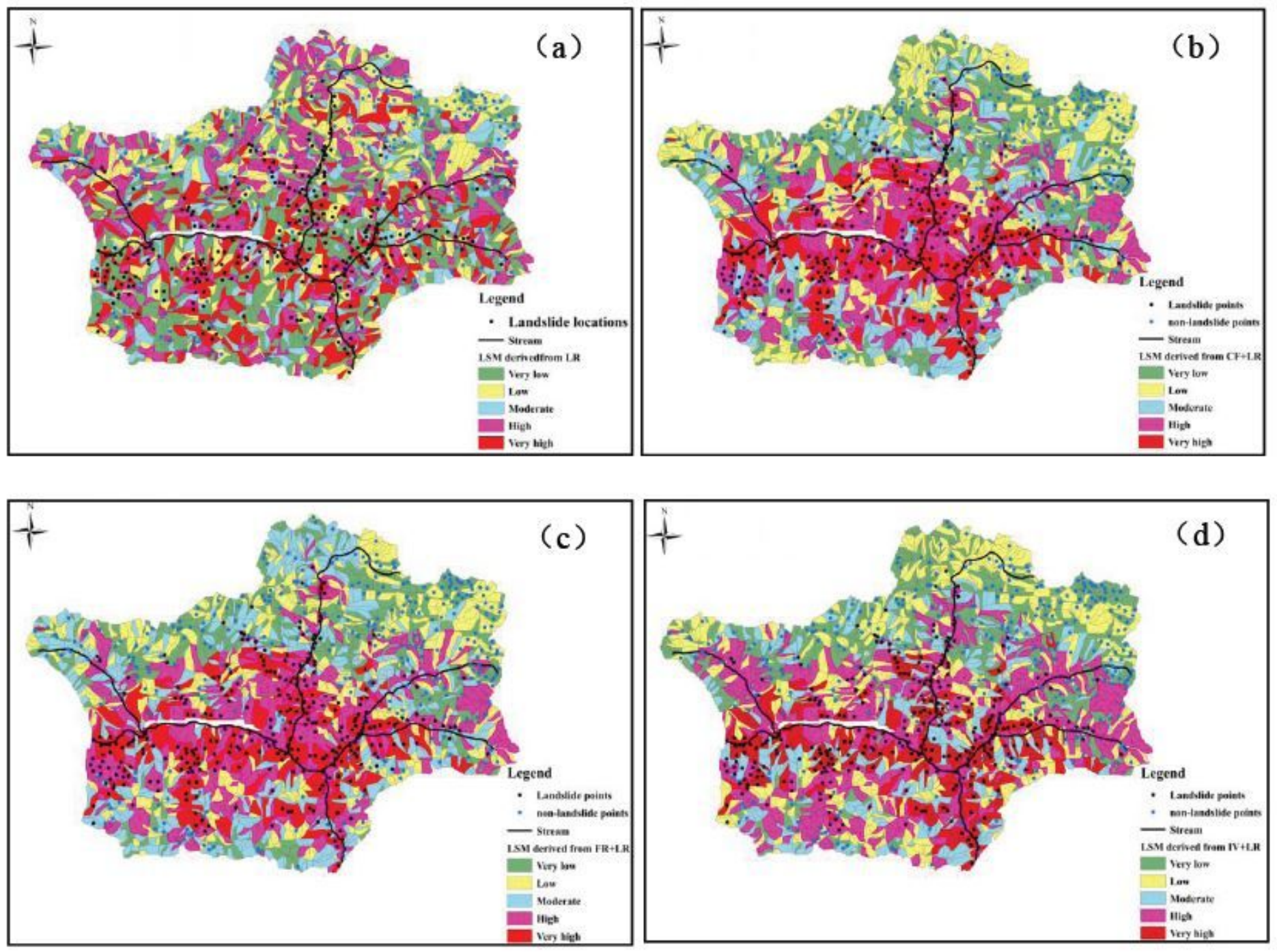

Figure 7

Landslide susceptibility maps: (a) LR model; (b) CFLR model; (c) FRLR model; (d) IVLR model. Note: The designations employed and the presentation of the material on this map do not imply the expression of any opinion whatsoever on the part of Research Square concerning the legal status of any country, territory, city or area or of its authorities, or concerning the delimitation of its frontiers or boundaries. This map has been provided by the authors. 

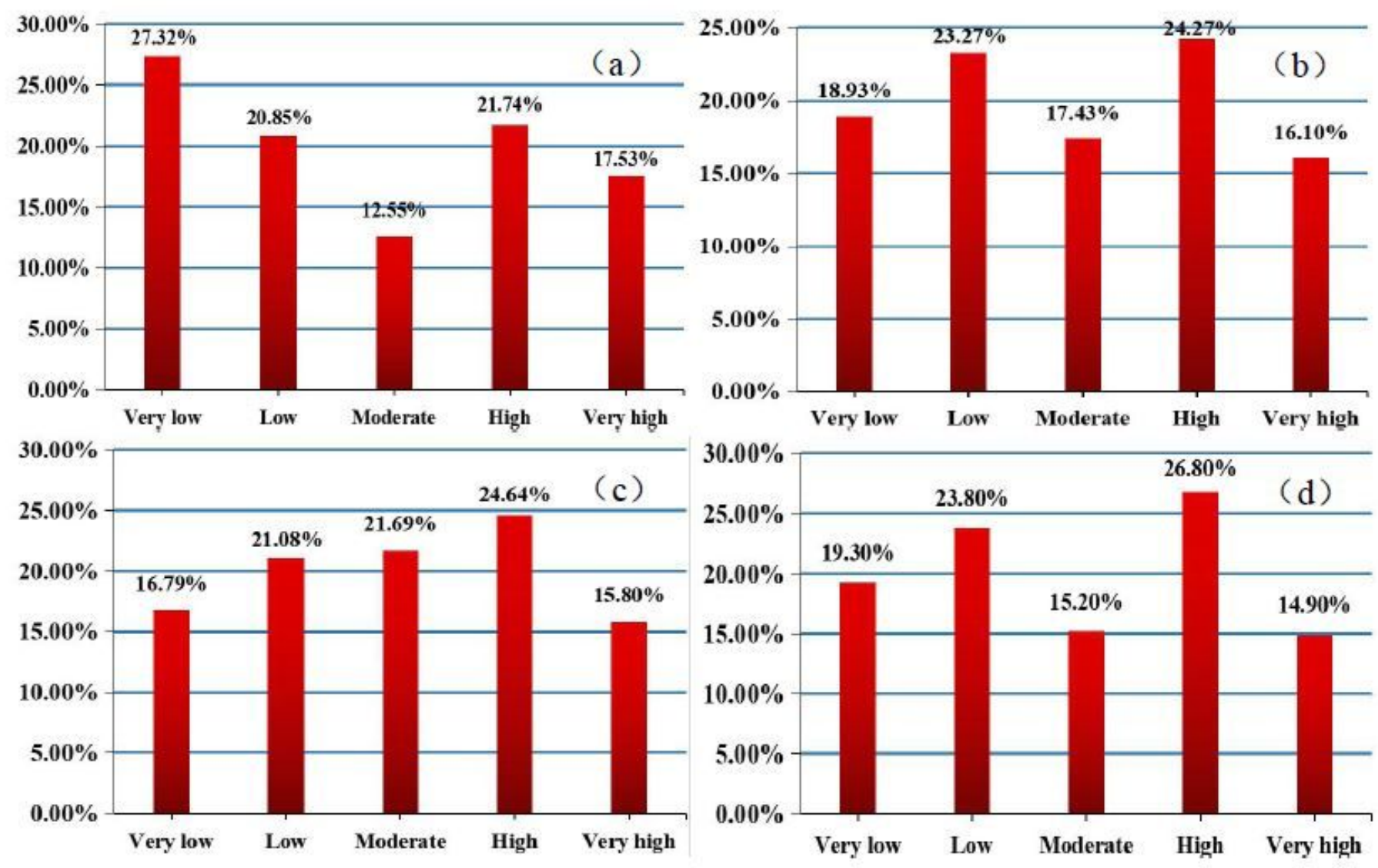

\section{Figure 8}

Percentages of areas in different susceptibility classes for landslide: (a) LR model; (b) CFLR model; (c) FRLR model; (d) IVLR model. 